\title{
Who Cares About Patents? Cross-Industry Differences in the Marginal Value of Patent Term
}

Neel U. Sukhatme

Georgetown University Law Center, nus6@georgetown.edu

Judd N.L. Cramer

Harvard University, Dept. of Economics, cramer@fas.harvard.edu

This paper can be downloaded free of charge from:

https://scholarship.law.georgetown.edu/facpub/2154

https://ssrn.com/abstract=2293245

American Law and Economics Review, Vol. 21, Issue 1, Spring 2019, Pages 1-45.

https://doi.org/10.1093/aler/ahz004

This open-access article is brought to you by the Georgetown Law Library. Posted with permission of the author. Follow this and additional works at: https://scholarship.law.georgetown.edu/facpub

Part of the Intellectual Property Law Commons, and the Law and Society Commons 


\title{
Who Cares About Patents? Cross-Industry Differences in the Marginal Value of Patent Term
}

\author{
Neel U. Sukhatme* and Judd N.L. Cramer**
}

March 29, 2019

* Associate Professor, Georgetown University Law Center; Affiliated Faculty, Georgetown McCourt School of Public Policy

** Lecturer in Economics, Harvard University Dept. of Economics 


\section{Abstract}

How much do market participants in different industries value a marginal change in patent term (i.e., duration of patent protection)? We explore this research question by measuring the behavioral response of patentees to a rare natural experiment: a change in patent term rules, due to passage of the TRIPS agreement. We find significant heterogeneity in patentee behavior across industries, some of which follows conventional wisdom (patent term is important in pharmaceuticals) and some of which does not (it also appears to matter for some software). Our measure is highly correlated with patent renewal rates across industries, suggesting the marginal value of patent term increases with higher expected profits toward the end of term.

The authors thank Orley Ashenfelter, Hank Farber, Alan Krueger, David Lee, Alexandre Mas, Bernard Black, Marco Ceccagnoli, Mingyu Chen, Wesley Cohen, Peter DiCola, Kwabena Donkor, Joshua Fischman, Michael Frakes, Ezra Friedman, Richard Holden, Scott Kostyshak, Paul Krugman, Andrew Langan, Mark Lemley, Pauline Leung, Inessa Liskovich, Katherine Litvak, Louis Kaplow, Alan Marco, Jonathan Masur, Steven Mello, Max Schanzenbach, David Schwartz, Steven Shavell, Jay Thomas, four anonymous referees, and discussants at Princeton University's Labor Seminar and Public Finance Working Group; U.S. Patent and Trademark Office, Office of the Chief Economist Brownbag Luncheon; Law and Economics Seminar at Harvard Law School; 2014 IP Scholars Conference (UC Berkeley); 2014 American Law and Economics Association Annual Conference (Univ. of Chicago); 2013 Conference on Empirical Legal Studies (Penn Law School); Law and Economics Colloquium at Northwestern Law School; 2013 Midwest Law and Economics Association Conference (Univ. of Illinois); PatCon4 (Univ. of San Diego); and Searle Center/USPTO Seventh Annual Conference on Innovation Economics (Northwestern Law School). Financial support from the Richard A. Lester Fellowship for Industrial Relations and the Clarence J. Hicks Memorial Fellowship in Industrial Relations is gratefully acknowledged. Gaurav Bagwe provided excellent research assistance. Any errors are the authors' own. 


\section{Introduction}

Since Nordhaus 1967 and Scherer 1972, scholars have debated what constitutes an optimal patent term - that is, the duration that maximizes the creation of socially valuable innovation net of social costs such as deadweight loss. The debate continues today, with some claiming the U.S. patent system is bloated and duration should be curtailed or even eliminated altogether, particularly for industries such as software, where patents are thought to be less important (Boldrin and Levine 2008). Others believe the current system works well enough, with patents encouraging the creation of new and useful inventions. Still others suggest problems might be industry-specific, e.g., Budish et al. 2013, and some claim we should move away from our current regime of uniform patent duration to one in which term is customized across technologies (Roin 2014).

A first step in evaluating these arguments and assessing what constitutes an optimal patent term is to measure the private value of patents to their owners. More specifically: how do patentees across industries differ in how they value patent duration? Why does this variation exist? And how might they respond to a marginal change in patent term rules? The last question is of particular policy importance, as reforms to the patent system are perhaps most likely to occur on the margins.

Previous attempts to answer these research questions have faced some limitations. Some prior studies, most notably Levin et al. 1987 and Cohen et al. 2000, use survey data to measure the relative importance of patents across industries. Levin et al. 1987 survey 650 high-level R\&D executives and find patents are particularly important in chemical and drug industries, but less so elsewhere. Cohen et al. 2000 survey 1,478 R\&D laboratories and find companies use a mix of patents, secrecy, and lead time 
to protect their intellectual assets, with patents typically used to block rivals from producing substitutes in chemical industries, and as negotiating levers in the telecommunications and semiconductor industries. Arora et al. 2008 use the same data to calculate patent premiums across different industry categories. While undoubtedly important, the relatively small sample size of these studies and inherent limitations of survey methodologies restrict the extent to which we can make fine-grained distinctions about the variable importance of patent protection. Moreover, these studies only capture self-reported estimates of the total value of patent protection; they do not measure a behavioral response to a change in patent term rules.

Other classic papers, such as Pakes and Schankerman 1984, Schankerman and Pakes 1985, and Pakes 1986, measure patent value via structural models that use data on patent maintenance fees, which are fees a patentee must pay to avoid expiration of her patent. Typically these papers use European patent data, as the European patent system requires more frequent renewal decisions than the American one. For example, Schankerman 1998, applying nonparametric techniques created by Pakes et al. 1989, uses patent renewal rates to measure the private value of French patents and their relative importance across industry categories.

Such renewal rates, however, are a relatively coarse measure of patent value, as they only tell us if a patentee valued her invention more than the cost of the maintenance fees, which are only in the hundreds or few thousands of dollars. Absent further assumptions, renewal rates do not necessarily inform us of the full distribution of patent values, nor do they let us easily distinguish among the majority of patents whose value exceeds the fee threshold. 
Somewhat relatedly, other papers explore whether patent counts - the number of patents awarded to firms or across industries in a unit of time - are good measures of economic activity and technological advancement (e.g., Abrams 2009; Griliches et al. [1986]; Lanjouw et al. [1998b]; Van Pottelsberghe et al. [2001]). These papers, however, do not measure the private value of patents to their owners.

Finally and most recently, Kogan et al. 2017 create a structural model and use a stock market event study methodology around the date of patent grant to measure the private value of patents. This approach, however, is limited to measuring aggregate patent value only as of the date of patent issuance; it does not separate out the marginal value of the last years of patent term. Moreover, their analysis is limited to patents owned by publicly-traded firms, which constitute a small fraction of all issued patents.

Most importantly, none of these prior studies directly measures the marginal response of patentees to changes in patent term rules. But the marginal value of duration is likely of special relevance to policymakers, as this is a policy lever they have previously used when reforming the patent system. ${ }^{1}$

We fill this gap in the existing literature by exploiting a rare natural experiment in which patent duration rules changed, when the United States adopted The Agreement

\footnotetext{
${ }^{1}$ As an example, consider the Drug Price Competition and Patent Term Restoration Act of 1984 (Hatch-Waxman Act), which allowed certain pioneer drugs to receive patent term extensions equal to one-half of the time they spend in the investigational new drug period before the Food and Drug Administration, subject to certain caps. The American Inventors Protection Act of 1999 (35 U.S.C. $\S 154(b)$ ) enabled patentees to recover some patent term for applications that take too long to process by the PTO. And Congress occasionally passes bills that extend terms on specific patents, in response to lobbying from the patent owners.
} 
on Trade Related Aspects of Intellectual Property Rights (TRIPS) in 1995. Prior to this law, a patentee received a fixed patent term that began only when a patent issued. Hence, if a patentee wanted to prevent her patent term clock from starting perhaps because she planned to commercialize her invention much later in the future - she could slow down the patent application process so that her patent would issue later. TRIPS, however, changed this dynamic by specifying that the patent term clock would start on the date a patent application was filed. So after TRIPS, a patent's effective term (i.e., the period where it could be used to file suit) was reduced by however long the inventor took to get her patent application approved.

Our approach is based on the simple idea that an applicant who cares about patent term would seize the opportunity presented by TRIPS — namely, by speeding up the patenting process (or equivalently, by no longer delaying this process), she could lengthen her effective patent term. Our hypothesis is that applicants in industries in which patent term is especially important would be more likely to speed up prosecution than applicants in industries in which term is less important.

To conduct our analysis, we construct a new dataset based on the transaction histories of 407,707 issued patents filed between 1994 and 1996. Because the patenting process (also known as patent prosecution) is a back-and-forth process between applicants and the U.S. Patent and Trademark Office (USPTO), we parse the data to determine what portion of prosecution time is attributable to the patent applicant. We find the average applicant sped up prosecution by about $4.16 \%$ due to TRIPS, thereby validating a prediction by Lemley 1994 .

More importantly, our approach allows us to develop a comprehensive measure of the marginal value of patent duration, based on the behavioral response of patentees to 
a change in patent term rules. We find this response varies greatly across industries. In line with conventional wisdom, we find pharmaceutical and chemical applicants are especially sensitive to patent term (Grabowski 2002), particularly in the field of genetics. More surprisingly, some software and computer applicants also sped up the patenting process, suggesting patent duration might be more important for them than is commonly believed (Wagner 2006). Other applicants, such as mechanical patentees, responded less to the change of law, indicating a lengthy patent term is of less importance to them.

To address potential selection issues created by applicants who anticipated the legal change, we test alternate specifications, including some where we exclude applications filed around the date the law went into effect and others where we test different measures of applicant delay. We obtain similar results and consistently identify the same industries as more sensitive to patent term change. ${ }^{2}$

Finally, we compare our new cross-industry measure of the marginal value of patent duration with two previous patent value measures. We find that our measure correlates both with the rate at which patentees pay maintenance fees, which as noted above, is a noisy measure of the late-term patent profits, as well as the survey-based measure created by Cohen et al. 2000 and used in Arora et al. 2008. While ours is the first comprehensive measure of the marginal value of a change in patent duration, this cross-validation exercise supports the notion that our approach credibly measures patent term sensitivity.

\footnotetext{
${ }^{2}$ Although we control for selection, in some ways selection is actually what we want to measure, since it implicitly tells us how much applicants care about the change in term rules. In other words, the industries in which the most selection occurs are the ones that care the most about patent term. We explore this possibility in more detail in section 2.6 below.
} 


\section{Measuring the Behavioral Response to a Change in Patent Term Rules}

\subsection{Empirical Strategy and Data}

Laws governing patent term rarely change. Since Congress established the patent system in 1790, the baseline term for a patent has changed only three times: in 1836 (increased from 14 to 21 years from patent issuance), 1861 (decreased to 17 years from patent issuance), and 1995 (changed to 20 years from patent application date). The rarity of such changes likely explains why applicant sensitivity to changes in patent term rules has been relatively unexplored by scholars.

Here, we exploit the 1995 rule change, when the United States adopted TRIPS. Prior to TRIPS, patents received a fixed 17-year term measured from the date on which the USPTO granted the patent application. After TRIPS, patent terms were increased to 20 years, but the start date was pushed earlier, back to the date the inventor applied for the patent. So post-TRIPS, if patent prosecution took two years, then a patentee would have 18 years of effective patent life, whereas if prosecution took four years, then a patentee would have only 16 years of effective patent life.

TRIPS, therefore, changed applicant incentives with respect to patent prosecution. ${ }^{3}$ After TRIPS, every additional day an applicant took to obtain a patent was one less

\footnotetext{
${ }^{3}$ Abrams 2009 explored a somewhat different aspect of this legal change, noting that certain patent classes have shorter average pendencies (time between patent application filing and patent issuance) than others. He suggested these classes would benefit disproportionately from the change in law, since they would receive longer patent term extensions on average due to the change in patent term rules caused by TRIPS. He showed that innovation, as measured by unweighted and citation-
} 
day of patent duration that she received. As such, we would expect patentees in industries in which term is especially important to respond to the change in law more than applicants in industries that are less term sensitive.

Of course, an applicant might also prosecute a patent application quicker if she wishes to obtain the patent sooner rather than later, perhaps because she wants to use it as an asset or to persuade would-be investors for funding, or to advertise or promote the product as patented as compared to patent pending. TRIPS, however, did not affect this incentive - both before and after TRIPS, a patent's effective term (i.e., the period where it could be used to file suit) began only after the underlying patent application issued. Hence, an applicant's desire to obtain a patent quickly would have existed both before and after TRIPS, which affected only when the patent term ended, not when it began. Thus, applicants' behavioral change after TRIPS was likely motivated by the additional patent duration they could gain at the end of term by speeding up prosecution.

Measuring this sensitivity to patent duration, however, is not as simple as measuring changes in total pendency - that is, the total time between when a patent application is filed and when it issues. Patent prosecution is a back-and-forth process - at some points, it is the applicant's turn to act and at others, it is the USPTO's. So to measure an applicant's sensitivity to changes in term rules, we must apportion the time an application is pending between the applicant and the patent office. Doing so allows us to identify which industries care most about patent duration, as applicants in that industry would respond most to the change in law.

weighted patent application counts, in fields with lower pendency increased disproportionately after TRIPS relative to application counts in fields with longer prosecution times. 
To measure applicant delay, we obtained data on every issued patent filed in 1994-1996 using the USPTO's Public PAIR (Patent Access Information Retrieval) database, as compiled by the USPTO's Office of the Chief Economist. This includes these patents' transaction history, which details every substantive or procedural action taken by the applicant or the USPTO.

After cleaning this dataset, we merged it with a patent dataset from NBER, described in Hall et al. 2001, that categorizes issued patents into broader industry categories based on patent classifications assigned by the USPTO during prosecution. Our final dataset includes 304,512 first-time applications ${ }^{4}$ and 103,195 continuation applications (ones that claim priority to a previously filed parent patent applications). ${ }^{5}$

To illustrate how we apportion time between the USPTO and the applicant for each patent, consider Figure 1, which shows a sample transaction history for U.S. Patent No. 5,515,068, titled "One Chip Semiconductor Integrated Circuit Device Capable of Outputting Analog Color Signal or Digital Color Signal." After a patent application is filed, the ball is in the USPTO's court, as the applicant typically waits for the agency to either issue a rejection or approve the patent claims. For most cases, the first substantive action taken by the USPTO is a non-final rejection. Here, we can see such a rejection was mailed by the agency on December 14, 1994. In our data,

\footnotetext{
${ }^{4}$ For a subset of first-time applications, we were able to supplement this data with attorney information assembled by Google from the PAIR database. Including controls for whether a patentee had an attorney or instead proceeded pro se (i.e., no registered attorney/agent was listed for the application) does not appear to materially affect our results.

${ }^{5}$ Some continuation applications were filed after June 8, 1995 (the date TRIPS went into effect) but claimed priority to an application filed before that date. Since these applications could claim the benefit of the pre-TRIPS patent term rules, we treated them as filed under that regime in our dataset.
} 
approximately $79.3 \%$ of patent applications received a non-final rejection like this at some point during patent prosecution.

To avoid abandonment of the patent application, an applicant must respond to such a rejection with an argument and/or an amendment to his patent claims, which define his invention. Applicants are typically given three months from the date a non-final rejection is mailed to file such a response, though they can pay a fee and request an extension of up to three months, giving them up to six months total to respond. Here, the applicant did not respond by the three-month deadline of March 14, 1995. Instead, the applicant requested and received a three-month extension, filing his response on June 14, 1995.

This back-and-forth process with the USPTO illustrates two ways of measuring applicant delay. First, we can measure the time an applicant took to respond to a non-final rejection, particularly the first non-final rejection she receives (since only a subset of rejected applicants receive multiple non-final rejections). ${ }^{6}$ After TRIPS, every day an applicant takes to respond to a patent office action results in one less day of patent term. This was not true pre-TRIPS. So applicants should, on average, speed up their response time to non-final rejections after TRIPS relative to before, with the effect most pronounced for inventors who are most sensitive to patent term.

\footnotetext{
${ }^{6}$ Frakes and Wasserman 2013 use a related variable, the average amount of time that the patent office takes to issue its first office action, as a measure of delay by the USPTO. They rely on annual summary data, disaggregated at the patent class and entity size level (e.g., average amount of time that the patent office took to issue a first office action for large-entity applicants filing patent applications related to cryptography in 1997), and was obtained via Freedom of Information Act requests.
} 
Second, we can measure how many extensions (if any) an applicant requested while prosecuting an application. In particular, we should expect to see fewer extensions requested by patent applicants when responding to non-final rejections post-TRIPS, since extensions increase prosecution time and hence decrease patent term. ${ }^{7}$

Returning to the sample transaction history, we can see this patent application was eventually granted, with the patent office mailing a notice of allowance on October 30, 1995. Before the patent could issue, however, the applicant was required to pay an issue fee. An applicant has up to three months to pay an issue fee or else the application is abandoned. Here, the USPTO recorded payment of the issue fee as "Issue Fee Payment Verified" on January 30, 1996. Previous empirical work has indicated the patent will then issue, on average, 6-8 weeks later (Crouch June 9, 2010). For our sample, we find the time between payment of the issue fee and patent issuance is positively correlated (0.5780) with the time between mailing of the notice of allowance and patent issuance. Figure 2 shows the nearly linear relationship between when the issue fee is paid and the average time when the patent issues. ${ }^{8}$

${ }^{7}$ For present purposes, we are not considering applicant responses to "final" rejections by the USPTO. The reason for this is that applicant responses to such rejections can be quite varied and difficult to categorize. In response to final rejections, applicants might file something called a "continuing prosecution application" - essentially, applicants pay an additional fee to get another crack at prosecuting before the examiner. Alternatively, applicants might file an appeal to the Board of Patent Appeals and Interferences. An applicant might also abandon his patent application.

${ }^{8}$ An applicant who plans to enforce her patent would have an incentive to pay her issue fee quickly, even if she does not immediately plan on filing a lawsuit, because damages for patent infringement are typically limited to infringing activities that occur after the patent has issued. So if an infringing activity is already ongoing, a patentee increases the damages she could receive if her patent issues faster. 
How long an applicant takes to pay an issue fee is thus a third way of measuring applicant sensitivity to patent term. Post-TRIPS, if a patent applicant wants to maximize her usable patent term, she will pay her issue fee quickly relative to what she would have done pre-TRIPS.

So our baseline empirical strategy is clear - look at the average time that patent applicants take to respond to non-final rejections, particularly their first non-final rejection, and to pay their issue fees, and see if this average decreased after TRIPS. ${ }^{9}$ We can also add up both of these types of delay to create a combined measure, which is what we do when creating our preferred measure of total applicant delay. Alternatively, we can look at the number of extensions requested post-TRIPS and see if that number decreased.

\subsection{Summary Statistics and Non-Parametric Graphs}

We begin with some summary statistics and non-parametric graphs to help describe the data. Table 1 shows shows summary statistics for six different time periods January 1 through June 7, and June 8 through December 31, for 1994, 1995, and 1996. These time periods roughly divide the year into halves, with the effective date on which TRIPS went into effect (June 8) as a dividing point. As can be seen, our outcome variables of interest appear to show changes in the directions that would be predicted (e.g., applicant delay spikes just before the change in law and then shows a sustained decrease). These results will later be confirmed in our regression analysis.

\footnotetext{
${ }^{9}$ In most specifications we use the time that applicants took to respond to the first non-final rejection they received. Our results remain the same, however, if we instead use the total time they took to respond to all non-final rejections and include a control for the number of office actions they received.
} 
Figure 3 shows how application pendency - the total time between patent application filing and patent application issuance - and applicant delay — the measure of time attributable to applicants during prosecution that we created using a detailed transaction history for each patent - evolved for patent applications filed between 1994 and 1996. A few trends stand out. ${ }^{10}$

First, we can see a spike in both application pendency and applicant delay just before June 8,1995 , which is the date TRIPS went into effect. The spike can be explained by TRIPS itself, which provided that any application filed prior to June 8, 1995, would receive the longer of 17 years from patent issuance and 20 years from application filing. ${ }^{11}$ Accordingly, some applicants might have taken advantage of this provision by choosing to file patent applications with longer expected pendencies prior to the change in law. ${ }^{12}$ We are mindful of these spikes and, as we discuss in detail below, account for selection around this date through a variety of alternate specifications in which we exclude applications filed around this date.

Second, we can see a steady increase in application pendency in 1994 and into 1995. By contrast, applicant delay remains relatively flat during this time. This divergence

${ }^{10}$ Since our preferred measure of applicant delay is the sum of the time that an applicant took to respond to a first non-final rejection plus the time he took to pay the issue fee, all graphs here are limited to the 323,256 issued applications that received at least one non-final rejection.

${ }^{11}$ In related work, we are conducting a stock market event study to measure how the retroactive application of TRIPS to previously-filed patents affected the values of patent-intensive firms.

${ }^{12}$ Some of these might be so-called "submarine patents," which are patent applications that inventors deliberately keep pending for a very long time. Lemley 1994. When such patents finally emerge from prosecution, they typically enter an already-mature industry in which competitors are susceptible to "patent hold-up," in which they must license the technology or else pay large fixed costs to redesign existing systems around the infringing technology. 
between application pendency (which includes delays attributable to the patent office as well as applicants) and applicant delay (which includes just applicant-induced delays) suggests that increases in pendency during these years were primarily driven by changes at the USPTO (i.e., the agency was taking longer to examine applications) rather than changes in applicant behavior.

Third, we see both pendency and applicant delay drop sharply after June 8, 1995, and then become quite stable, with perhaps a slight decrease over time. Thus, the graphs suggest there was a trend break in both pendency and applicant delay around June 8, 1995.

Finally, further visual evidence of the effect of TRIPS is shown in Appendix Figure A.1, which shows coefficients for month dummies (with standard error bands) between January 1994 and December 1996, when regressed on applicant delay. We can see a spike in June 1995 (month 18 in the graph), when TRIPS went into effect, followed by a sustained drop afterward.

We might wonder whether the apparent trend break in June 1995 affected only certain categories of inventions, or whether its effect is more widespread. Figure 4 and Appendix Figure A.2 show changes in applicant delay and pendency, respectively, by NBER category. Appendix Figure A.2 shows that pendency was increasing across all categories prior to the law change, and it appears to stabilize or drop slightly across most categories after TRIPS goes into effect. Figure 4 shows that applicant delay drops significantly, particularly for the Drugs \& Medical, Computers \& Communications, and Chemicals categories. The Mechanical and Others categories appear to be the least affected groups, and Electrical \& Electronics falls in the middle. We will discuss these results in more detail in section 2.5 below. 
We can also test for a trend break due to TRIPS using non-parametric methods. Appendix Figure A.3 shows local polynomials with standard error bands that plot applicant delay relative to time. The polynomial on the left runs from January 1, 1994, to June 7, 1995; the polynomial on the right runs from June 8, 1995, to December 31, 1996. The left-hand polynomial tips upward prior to the cut date, suggesting some applicants chose to file some especially long pendency applications during this time. But there is still a significant break between the two graphs, where the local polynomial after June 8 is significantly lower than the polynomial before June 8. Moreover, applicant delay drops precipitously after June 8, suggesting applicants quickly changed their behavior and sped up patent prosecution under the new regime.

\subsection{Results Using Applicant Delay Measure}

To validate the suggestive graphical evidence discussed above, we present a number of ordinary least squares regressions that test how applicant behavior changed around the passage of TRIPS. Table 2 shows the effect of TRIPS on our preferred measure of applicant behavior, applicant delay. ${ }^{13}$ In particular, our "Post-TRIPS" dummy

${ }^{13}$ Apart from a few outliers, applicant delay is not highly skewed, with an overall mean of 189.75 and standard deviation of 76.88 for the 323,256 applications that received at least one office action. Indeed, only 2,332 of these observations $(0.721 \%)$ have applicant delays that exceed 500 days. The two components of our applicant delay measure also do not appear highly skewed - the amount of time applicants take to respond to a first office action has a mean of 112.45 and standard deviation of 56.40 for 323,356 applications; and the time applicants take to make the final issue fee payment has a mean of 77.27 and standard deviation of 48.27 for 407,707 applications. As such, we keep applicant delay in levels for our preferred specifications. Nonetheless, we also show various log specifications for robustness and because those specifications allow for straightforward percentage point comparisons across invention categories. 
variable specifies whether a patent application was filed on or after June 8, 1995, when the new patent term regime went into effect. In our most parsimonious model presented in column (1), applicant delay is regressed on a Post-TRIPS dummy. We see the average applicant delay fell by about 8.03 days (4.16\%) following TRIPS.

In columns (3), (4), (7), and (8), log applicant delay is instead the dependent variable (with all coefficients and standard errors multiplied by 100). This specification enables us to interpret the change in applicant prosecution speed as a percentage point change. Looking at columns (3) and (4), we can see that applicant delay overall fell by about 4.2 to 4.6 percentage points following TRIPS.

Due to possible concerns about selection around the implementation of TRIPS, we also present specifications where we exclude periods when one might worry most about changed applicant behavior. Our results remain highly significant and of a similar order of magnitude when we exclude the period between December 8, 1994 (when TRIPS was enacted) and August 8, 1995 (two months after it went into effect) — see columns (2), (4), (6), and (8). ${ }^{14}$

In columns (5)-(8), we add numerous controls. Because an applicant's prosecution behavior might depend on the number of back-and-forth interactions he has with the patent office, we include controls for the number of non-final office actions and number of restriction requirements ${ }^{15}$ for each patent application. In addition, we add fixed-

${ }^{14}$ Our results remain robust when we exclude larger windows, such as when we exclude all of the data from 1995.

${ }^{15} \mathrm{An}$ examiner issues a restriction requirement when an applicant claims more than one "independent and distinct invention in a single application," and when the patent examiner would face a "serious burden" if forced to examine each of these inventions. In our data, $10.85 \%$ of patent applications received a restriction requirement at some point during patent prosecution. 
effects for patent assignee (essentially a firm fixed effect), ${ }^{16}$ and patent class (i.e., type of invention as classified by the USPTO). We also control for the amount of delay attributable to the patent office (remainder), by subtracting the total applicant delay (i.e., the total time the ball was in the applicant's court) from the pendency of the application. In these specifications, we further control for whether the applicant is a small entity, which affects the magnitude of fees charged by the USPTO, and whether the patentee was from the United States. Moreover, including interactions of the various controls described here or including fixed effects for patentee's country of origin do not appear to materially change the results.

In addition, we control for whether an application claimed priority to a previous patent application. Applications that are continuations of earlier applications (continuation), that are national stage applications based on previous foreign or Patent Cooperation Treaty filings (nat'l stage), or that are appealed to the Board of Patent Appeals and Interferences (appealed) appear to have longer applicant delays. Divisional applications (filed in response to a restriction requirement) have shorter applicant delays. ${ }^{17}$

In response to a restriction, a patent applicant must file an election in which the applicant chooses which invention to pursue in the present application. Additionally, the applicant may traverse, or dispute the restriction, and he may also pursue the other inventions, if desired, in separate divisional applications. The applicant is generally given one month to respond from the date the restriction requirement is mailed, although the applicant can pay a fee and request an extension of up to five months, giving him up to a total of six months to respond.

${ }^{16} 2.38 \%$ of all observations $(9,714$ of 407,707$)$ have more than one assignee. These patents are excluded in regressions that include assignee fixed effects; results are similar if these assignees are included.

${ }^{17}$ Note that our results remain robust if we exclude all applications that claim priority. 
The inclusion of the controls substantially reduces our applicant delay coefficient across all specifications. We can see this coefficient decreases from -8.03 to -3.32 for the specifications that include all filings, and from -8.69 to -2.97 for the specifications that exclude the inner window. In our log specifications, the controls reduce the applicant delay coefficient from -4.21 to -1.64 for the specifications that include all filings, and from -4.62 to -1.46 for the specifications that exclude the inner window.

We are mindful that some of these controls might instead be considered outcome variables. For example, we might expect some applicants were less likely to seek a continuation after TRIPS, since doing so would now reduce patent term. Regardless, our coefficient remains significant and negative across all specifications. While our full covariate specifications in columns (5)-(8) are the preferred specifications we use in our later graphs and analysis, we also present results throughout the paper and in our Appendix using our more parsimonious specifications in columns (1)-(4). We find our results largely unchanged depending on the specification we choose, which provides more support for the robustness of our results.

One might be concerned that the above results were driven by a downward time trend in our preferred measure of applicant delay. We can control for this possibility by including time variables in our OLS regressions. These specifications, which we show in Table 3, include both linear and quadratic time variables. To test for a trend break we also include interactions of time and time*time with Post-TRIPS in our original models. The coefficient on Post-TRIPS remains negative across all specifications; it is statistically significant at the $5 \%$ level for the specification in column 1, nearly significant at the $5 \%$ level for the specification in column 2, and not significant for the specification in column 3. At any rate, the statistic of interest is the F-test which tests for equality between the Post-TRIPS variable and its interactions with 
time, a continuation of trend. The null hypotheses are rejected handily in all three specifications. This outcome also holds for the individual applicant delay components, helping to allay possible concerns about divergent trends influencing our results.

\subsection{Results Using Disaggregated Measures of Applicant De- lay}

To verify applicants sped up prosecution over the entirety of patent prosecution, Tables 4 and 5 present the outcome of similar regression analyses on disaggregated measures of applicant delay. Table 4 focuses on extension requests from patent applicants. An extension request (which is almost always granted) provides an individual extra months to respond to a patent office action, such as a non-final office action or restriction requirement. So cutting down on extensions is a clear way for an applicant to decrease prosecution time.

Looking at the raw data, $40.05 \%$ of pre-TRIPS applicants requested extensions, as compared to $36.27 \%$ of post-TRIPS applicants. Columns (1) through (3) present OLS results showing that the average number of extensions fell after TRIPS. Columns (4) through (6) present the marginal effects of logistic regressions on whether an applicant applied for at least one extension. Once again the coefficient on PostTRIPS is negative and highly significant, suggesting that the share of applications with an extension fell by 3.0 to 4.1 percentage points.

In Table 5, we see other measures of applicant delay also decreased on average after TRIPS went into effect. Columns (1) to (3) show that applicants after TRIPS on average responded significantly faster to non-final office actions, conditional on having received one. Applicants also paid their issue fees sooner, as shown in columns (4) 
to (6). In columns (7) to (9), the outcome variable is whether an application is a continuation of a previous application. We can see applicants are less likely to file continuations post-TRIPS - this makes sense, as the marginal cost of a continuation would be higher after TRIPS, since it would result in a shorter patent term. These results remain highly statistically significant across different time periods and with the inclusion of the same rich set of controls and fixed effects as described above. Taken together, these different measures of applicant delay give a consistent picture: applicants sped up numerous facets of patent prosecution in response to TRIPS.

\subsection{Cross-Industry Differences in Applicant Behavior}

We now see how applicants in different industries varied in their response to TRIPS. When assembling the NBER dataset, Hall et al. 2001 consolidated the over 400 classes used by the USPTO to categorize inventions into 37 subcategories and six categories. Figure 5 below shows coefficients for the Post-TRIPS dummy variable with standard error bars for these six categories - Chemicals, Computers \& Communications, Drugs \& Medical, Electrical \& Electronics, Mechanical, and Others (a residual category). We present results using our full set of controls, with both applicant delay and log applicant delay as the outcome variables of interest, as used in the specifications in columns (5)-(8) of Table 2.

As Figure 5 shows, the largest effect (most significant decrease in applicant delay) appears to be in the Drugs \& Medical and Computers \& Communications categories, followed by the Chemical, Others and Electrical \& Electronics categories. The Mechanical category appears to have been affected relatively little by TRIPS, suggesting that applicants in that category were less sensitive to the change in patent term 
rules. We see the results are largely similar, though with reduced magnitudes, when we exclude data from December 8, 1994, to August 8, 1995.

One gets a clearer picture of cross-industry differences by looking at the 37 component subcategories of the six larger categories. Table 6 shows Post-TRIPS coefficients for these groups, again looking at the coefficients based on specifications (5)-(8) from Table 2. We can see that coefficients vary across specifications, but by and large, the most negative coefficients are for Communications, Computer Hardware and Software, Drugs, Electrical Lighting, Electronic Business Methods and Software, Genetics, Measuring and Testing, Organic Compounds, and Semiconductor Devices. ${ }^{18}$ While patents are typically thought of as being important for some of these categories, most subcategories in Computers and Communications also have large negative coefficients. These results are a bit more surprising, as the value of computers and particularly software is conventionally thought to be less dependent on patent law than other technological areas. ${ }^{19}$

\subsection{Cross-Check Using Patent Count Measure}

As noted previously, selection around the date TRIPS went into effect (June 8, 1995), is a potential concern. But one could instead view selection as yet another measure

${ }^{18}$ As additional robustness checks, Appendix Table A.1 presents results when we instead run the same analysis using the specifications without controls as shown in columns (1)-(4) of Table 2.

${ }^{19}$ While our results suggest some software patents have more long-term value than is conventionally believed, it's not clear why this is true. It's possible this value might stem from the broader and more ambiguous scope of some of these patents, which allow them to be useful in litigation even when the underlying invention has become obsolete. In other words, it is possible some software patents have long-term private value yet are socially deleterious. 
of applicant sensitivity to patent term. Put differently, industries in which selection is greater might be the same industries in which applicants care more about patent term. If so, this sort of selection-based measure should correlate with our post-TRIPS measure, which also measures cross-industry differences in patent term sensitivity. ${ }^{20}$

In constructing a selection-based measure, we use patent counts - namely, the number of patent applications filed in a particular industry category within a fixed period of time. One plausible measure of selection is the number of patent applications filed before TRIPS went into effect. As Figure 6 shows, the number of patent applications spiked across all patent categories in the week prior to June 8, 1995, suggesting that many inventors filed applications just before the new patent term regime took effect. The size of this spike varied greatly across categories - for example, Drugs \& Medical applications increased nearly 52 -fold, from an average of 53.75 per day in November 1994 to 2,783 on June 7, 1995, the day before TRIPS went into effect. By contrast, Computers and Communications grew from about 116.22 per day to 1712 (nearly 15-fold increase) and Mechanical went from about 95.94 per day to 989 (over 10-fold increase) during that same period. The heterogeneity across categories shows patent applicants in different industries reacted differently to TRIPS.

To normalize our patent count measure, we divide the number of patent filings per category by the number of filings from the same time period in the previous year. More formally, our patent count measure is:

$$
\text { Count }_{i}=\frac{\# \text { of patent apps. in category } i(6 / 1 / 95-6 / 7 / 95)}{\# \text { of patent apps. in category } i(6 / 1 / 94-6 / 7 / 94)}
$$

${ }^{20}$ We thank Michael Frakes for this insight. 
Our patent count measure is shown for each NBER subcategory in the last column of Table 6. This measure is negatively correlated with our primary measure of applicant delay, the post-TRIPS coefficient, regardless of the specifications we use from Table $2 .{ }^{21}$ This means the industries in which applicants sped up prosecution post-TRIPS are by and large the same industries whose application filings increased the most in the week prior to TRIPS' effective date of June 8, 1995, as compared to filings from a year earlier. The correlation between these measures provides another cross-check that our post-TRIPS coefficient accurately captures cross-industry differences in term sensitivity.

\subsection{Other Changes in TRIPS}

The change in term rules was TRIPS' most significant change to patent law, which we believe drove the changes we observe in applicant behavior. Nonetheless, we also check whether other changes initiated by TRIPS (Van Horn 1995) might affect our results here. First, TRIPS changed rules relating to establishing an invention date by allowing (for the first time) applicants to establish patent priority based on inventive activity outside of the United States, not just limited to the filing of an international application under the Patent Cooperation Treaty or the filing of a foreign patent application. This seems unlikely to systematically affect the prosecution time of applicants. Regardless, controlling for the country of origin of the patent applicant

${ }^{21}$ Specifically, the correlations are: $-0.72,-0.68,-0.73,-0.67,-0.44,-0.42,-0.42,-0.37$ between the count measure and the post-TRIPS coefficient obtained based on the specifications in columns (1)(8), respectively, of Table 2. All correlations except for those generated based on columns (6) and (8) are statistically significant at the $1 \%$ level; those two correlations are statistically significant at the $5 \%$ significance level. 
(something we tested in unreported specifications) should capture at least some of this effect, and it did not substantially affect our results.

TRIPS also allowed patentees to obtain extensions to their patent term in certain limited situations - when patent issuance is delayed due to an interference proceeding (where two separate inventors dispute who invented first and go through an extensive regulatory process to determine who has priority), a secrecy order (which requires a patent prosecution to remain secret if a government agency believes it to be in the interests of national security), and a successful appellate review. Interferences are very rare — between 1991 and 1994, there were only 718 interferences, much less than $1 \%$ of all applications (Calvert and Sofocleous 1995). Secrecy orders appear to be even rarer (at least prior to September 11, 2001), and most of these cases are unlikely to appear in our sample. And appeals involve relatively few cases, with even fewer being reversed (e.g., in fiscal year 1998, there were 3,779 appeals received and only 1,239 reversed (U.S. Patent \& Trademark Office 1998)). About $5.59 \%$ of the patents in our sample $(22,808$ out of 407,707$)$ appear to been appealed at some point. At any rate, our results remain robust when we either exclude or control for cases involving appeals.

TRIPS also created a new type of patent application known as a provisional patent application, which is a simplified application (typically without formal claims) that establishes a priority date for the applicant. Provisional applications do not extend patent term; they simply provide a placeholder for applicants to follow up within one year with a standard, non-provisional application. An applicant who files a provisional and then a follow-up non-provisional within one year gets the priority date of the provisional filing, but receives the standard term of 20 years from the filing of the 
non-provisional application. Provisional applications that are not followed up with a non-provisional application are abandoned.

One concern might be if applicants who systematically differ in delay chose to file provisional instead of non-provisional applications after TRIPS. For example, perhaps applicants who wanted to delay the start of prosecution post-TRIPS filed provisional applications instead of non-provisionals. If we looked at only non-provisionals and ignored the provisionals, we would introduce a selection bias in our results.

There are reasons to believe this is not an issue here. First, provisional patent applications were not common in the period right after TRIPS was enacted. If many applicants preferred to wait until TRIPS went into effect to file provisional applications, we would likely see a spike of applications after that date. But in our sample, we observe only 111 issued patents filed in 1995 and 3,622 issued patents filed in 1996 that claim priority to provisional applications. These are small numbers compared to the 285,523 issued patents filed in 1995-96 in our sample. Moreover, including these applications in our sample, with or without controls, or excluding them altogether does not meaningfully change our results.

\section{Cross-Validation of Measure of Marginal Patent Term Value}

We now compare our cross-industry measure of marginal term value with other patent value measures. This cross-validation exercise provides further support that our approach credibly measures patent term sensitivity. 


\subsection{Maintenance Fees as a Measure of Late-Term Patent Value}

One might expect that applicants who speed up prosecution the most in response to TRIPS do so because they have the most to gain at the end of their patent term. Intuitively, if applicants in a certain industry systematically expect their underlying inventions to be valuable far into the future, those applicants would be incentivized to delay prosecution in the pre-TRIPS era, so that their patents would issue later. After TRIPS, this distortion would be removed, causing such applicants to speed up prosecution relative to applicants in other industries.

Here, we empirically show how our measure of prosecution "speed up" relates to a different measure of late-term patent value: the proportion of patents within invention categories that do not lapse for failure to pay patent maintenance fees (also known as patent renewal fees). As background, the USPTO requires applicants to pay three maintenance fees, due at $3 \frac{1}{2}, 7 \frac{1}{2}$, and $11 \frac{1}{2}$ years after patent issuance. If a patentee does not pay these fees, then his patent will lapse, which means its term will end immediately rather than at its scheduled time. The amount of maintenance fees is uniform across industry categories; in 1995 , it was $\$ 650, \$ 1,310$, and $\$ 1,980$, for $3 \frac{1}{2}$, $7 \frac{1}{2}$ and $11 \frac{1}{2}$-year maintenance fees, respectively. ${ }^{22}$ If a patent assignee qualifies as a "small entity" - that is, if it is an individual, or a small business or non-profit organization that meet certain criteria - then these fees are halved. About $25 \%$ of patents issued between 1981 and 2000 qualified for "small entity" status.

Scholars have long used data on maintenance fee payments as a measure of patent valuation. (e.g., Lanjouw et al. 1998a, Schankerman 1998, Allison et al. 2003, Moore

${ }^{22} 35$ U.S.C. $§ 41$ (1995). 
2005, Bessen 2008, Pakes and Schankerman 1984, Pakes 1986). The idea is that if a patentee chooses to pay a maintenance fee, we can infer the patentee believes the expected benefit from keeping the patent alive exceeds the present cost of the maintenance fee. More specifically, maintenance fees tell us something about discounted expected profits from patents toward the end of their term. For example, a profit-maximizing patentee would renew a patent at $11 \frac{1}{2}$ years only if the discounted expected value of future profits stemming from the patent exceeds the maintenance fee payment at that time.

Accordingly, we can use maintenance fee payments as a rough measure of the relative value of patents across industries, particularly their late-term patent value. For example, if pharmaceutical patents are more likely to be maintained on average than mechanical patents, then we might conclude that pharmaceutical patents are on average more valuable than mechanical patents. Of course, this conclusion only holds true for patents near the top end of the patent value distribution - that is, those patents whose value exceeds the maintenance fee threshold amount. It might not hold true for less valuable patents within a patent category. In short, maintenance fees cannot tell us the precise distribution of patent values within industries (Abrams et al. April 8, 2013). Nonetheless, a higher rate of renewal within an industry category, particularly at the $11 \frac{1}{2}$ year date, suggests that on average, patents in that industry are worth more toward the end of their term than in industries with lower renewal rates. So we might expect to see some correlation between industries that have higher renewal rates and industries in which applicants sped up prosecution the most in response to TRIPS. 
The data in Table 6 show the percentage of patents filed between 1994 and 1996 that were maintained through $11 \frac{1}{2}$ years within the 37 subcategories described above. ${ }^{23}$ It also shows the post-TRIPS coefficients using our specifications in columns (5) , (6), (7), and (8) of Table 2. Figure 7 also shows our results graphically in a scatterplot.

Even though there are only 37 subcategories, we see a strong and significant negative correlation between the maintenance fee measure and our measures of applicant delay. ${ }^{24}$ This suggests patentees who are most likely to maintain their patents are in the same industries as the patent applicants who sped up prosecution the most in response to TRIPS. We find similar strong correlations when we compare our measure with patent renewal rates from other years.

The correlation between our measure of patent delay and the renewal rate within a particular industry supports our model of patenting behavior. Namely, patent classes that are most likely to be maintained - and hence, have the highest profit remaining near the end of term - are the same patent classes whose applicants responded the most to TRIPS. In other words, the correlation between these measures suggests that post-TRIPS, applicants who had more profits to lose at the end of their patent term were the ones most likely to speed up patent prosecution.

\footnotetext{
${ }^{23}$ To isolate the late-term hazard, we also tested how our post-TRIPS coefficient correlates with the $11 \frac{1}{2}$ year renewal rate conditional on a patent being renewed at $7 \frac{1}{2}$ years. When we conduct this robustness check, we find substantially the same correlations and results as in our analysis here.

${ }^{24}$ Specifically, the correlations are: $-0.44,-0.50,-0.35,-0.39,-0.33,-0.45,-0.23,-0.31$ between percent maintained and the post-TRIPS coefficient obtained based on the specifications in columns (1)(8), respectively, of Table 2. The correlations based on columns (1), (2), and (6) are statistically significant at the $1 \%$ level; the correlations based on columns (3), (4), and (5) are statistically significant at the $5 \%$ level; and the correlation based on column (8) is statistically significant at the $10 \%$ level.
} 
An advantage of our approach is that it is a more complete measure of patent value than maintenance fees. As noted, the latter only tell us if a patentee valued her invention more than the (relatively low) cost of the renewal and do not necessarily inform us of the full distribution of patent values absent further assumptions.

\subsection{Survey-Based Measure Based on Cohen et al. 2000 and Arora et al. 2008}

Finally, we compare our patent term sensitivity measure with a survey-based measure introduced in Cohen et al. 2000 and used in Arora et al. 2008. In Cohen et al. 2000, the authors surveyed 1,478 R\&D laboratories, who reported the relative importance of patents for their firms. The authors found that patents were particularly important for blocking rivals from producing substitutes in chemical industries, and as negotiating levers in the telecommunications and semiconductor industries. In Arora et al. 2008, the authors applied this survey data to a structural model to calculate an unconditional expected premium for patents in 19 broad invention categories, as well as an expected premium conditional on patenting in those areas.

The authors provided SIC classifications for 17 of these invention categories. ${ }^{25} \mathrm{We}$ used this mapping to match these categories with their corresponding 1997 North American Industry Classification System (NAICS) classifications via a concordance provided by the U.S. Census. ${ }^{26}$ This resulted in 491 NAICS groups, some of which

\footnotetext{
${ }^{25}$ The paper lumped together two categories — drugs and medicines, and biotech — when mapping
} to SIC classifications, so we averaged these categories in our analysis below. The paper also did not provide SIC classifications for one category, "Other Electrical Equipment."

${ }^{26}$ Available at https://www.census.gov/eos/www/naics/concordances/concordances.html. 
mapped to multiple invention categories. To reduce these multiple mappings, we associated NAICS groups that matched a more specific category (e.g., "Rubber") with that category if that same group also matched a more general residual category (e.g., "Other Chemicals"). We dropped the remaining groups that spanned multiple invention categories and ended up with 469 unique NAICS-invention group mappings.

Next, we relied on Lybbert and Zolas 2014, which provides a cross-walk between 1997 NAICS classifications and U.S. patent classifications (USPCs). Specifically, the crosswalk generates a probability distribution for each NAICS group over various USPCs. We then calculated regression coefficients for our applicant delay measure using the specifications in columns 1 and 5 of Table 2 for each USPC group with at least 100 patents in our sample. Using the probability distributions in Lybbert and Zolas 2014, we aggregated the coefficients to create a coefficient for each NAICS group. Finally, because most invention categories contained multiple NAICS groups, we aggregated across these groups to obtain a coefficient at the invention group level. We used equal weights across NAICS groups for this step.

The final results of our analysis are presented in Table 7, and shown graphically in Figure 8. Even with just 17 invention categories, our measure of marginal patent term value is negatively correlated with the patent premium measures at at least the $10 \%$ significance level (-0.478 and -0.490 for the coefficient from column 1 , and -0.429 and 0.430 for the coefficient from column 5 for the unconditional and conditional expected patent premium measures, respectively). This suggests the invention categories in which applicants sped up most due to TRIPS were the same categories that Arora et al. 2008 identified as having higher patent value. 
Our approach differs from Cohen et al. 2000 and Arora et al. 2008 in that we directly measure the behavioral response of patentees to a change in patent term rules. This enables us to measure the marginal value of patent duration at a much finer-grained level. Still, that our results correlate with these previous studies bolsters our claim that our method accurately measures the private value of patents.

\section{Conclusion}

We use a rare natural experiment to measure how sensitive patentees in different industries are to a change in patent term rules. In particular, we examine how applicants in different industries differentially sped up patent prosecution in response to the TRIPS agreement, which decreased patent length one day for every day the patent was prosecuted.

To calculate this measure, we construct a novel dataset based on the transaction histories of 407,707 issued patents filed between 1994 and 1996. We apportion prosecution time between the patent office and applicant, thereby creating the first comprehensive measure of applicant prosecution time. We find that applicants in different industries varied greatly in their response to the law. Our results generally support previous theory, though computer and software products appear more sensitive to patent term than was perhaps previously appreciated.

These results are robust across many specifications. We deal with potential selection around the date TRIPS went into effect by excluding various inner windows around that date. We also exploit any selection itself as an independent cross-industry measure of term sensitivity, and find it is correlated with our applicant delay measure. 
Finally, we find that our applicant delay measure significantly correlates with the rate at which patents are maintained across industries, as well as self-reported, industrybased measures of patent value, as introduced in Cohen et al. 2000 and used in Arora et al. 2008. This cross-validation gives us further confidence we have credibly measured the marginal value of patent term across industries through the behavioral response of patentees to a change in term rules.

\section{Figures}

Figure 1: Sample Transaction History

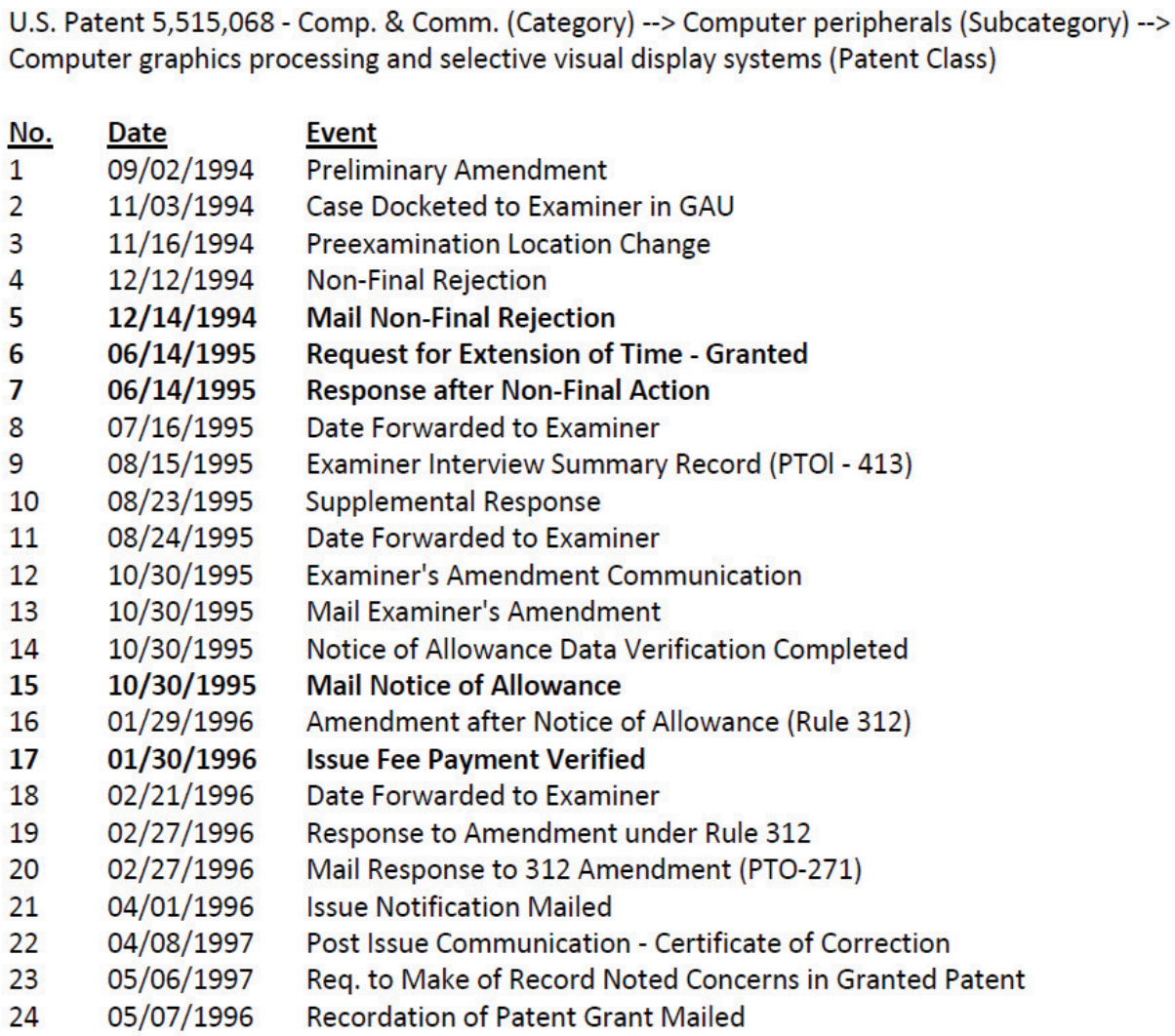


Figure 2: Issue Fee Payment Date and Average Patent Issuance Date

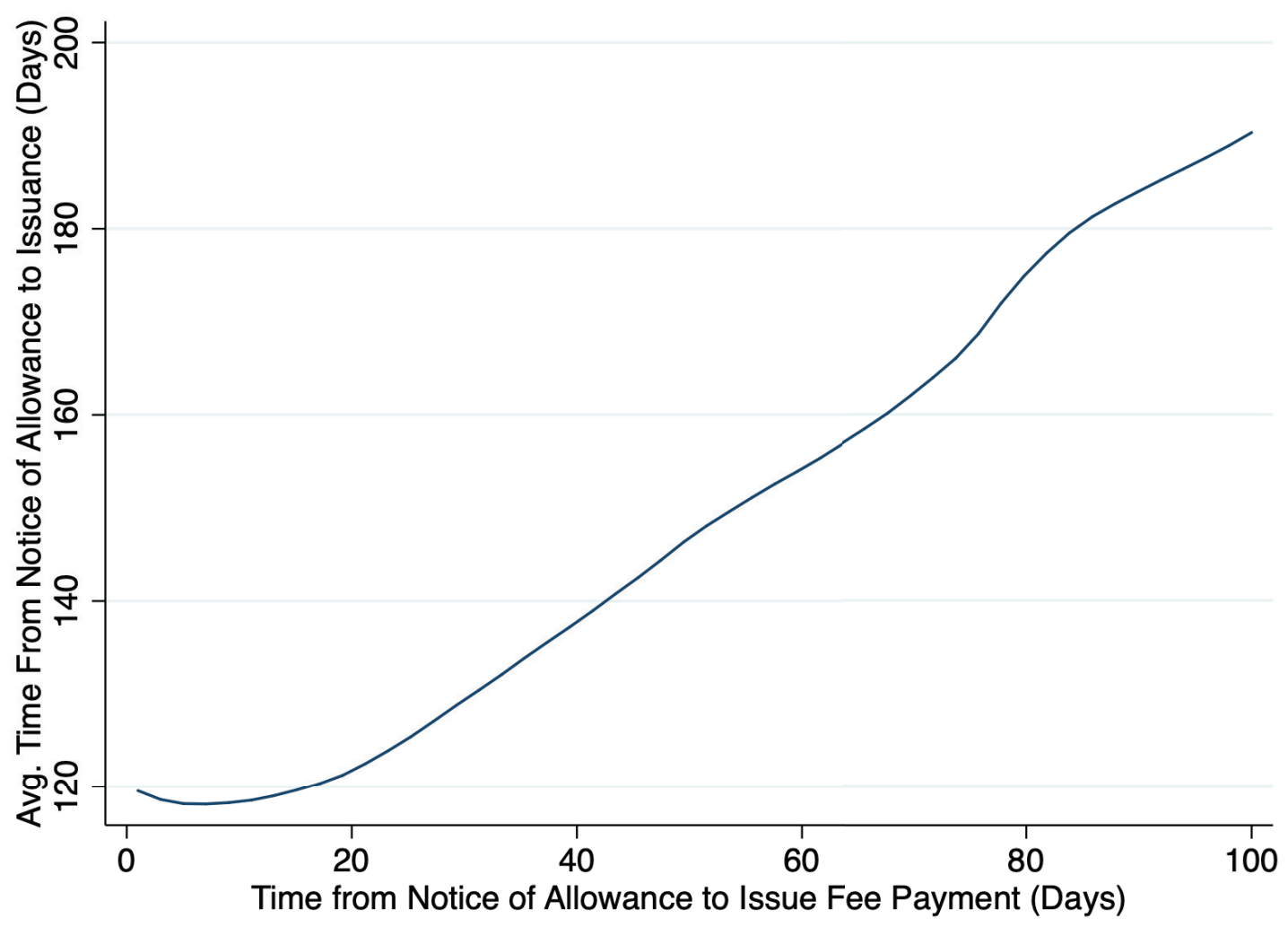

Notes: This figure compares issue fee payment date and average patent issuance date, both measured from the date a notice of allowance was mailed. It shows a local polynomial regression using an Epanechnikov kernel of degree 0 and a one-week bandwidth and is based on data from 547,424 patents issued in 1994-1998. The graph excludes $2.31 \%$ of patents $(12,642$ of 547,424$)$ for which the time between the mailing of the notice of allowance and the issue fee payment exceeded 100 days. Such applications likely correspond to extraordinary cases, such as where applicants failed to pay their issue fee in a timely manner and had to petition the USPTO for late payment. Regardless, a similar, nearly linear relationship appears when graphing dates corresponding to these excluded patents. 
Figure 3: Application Pendency and Applicant Delay: 1994-1996

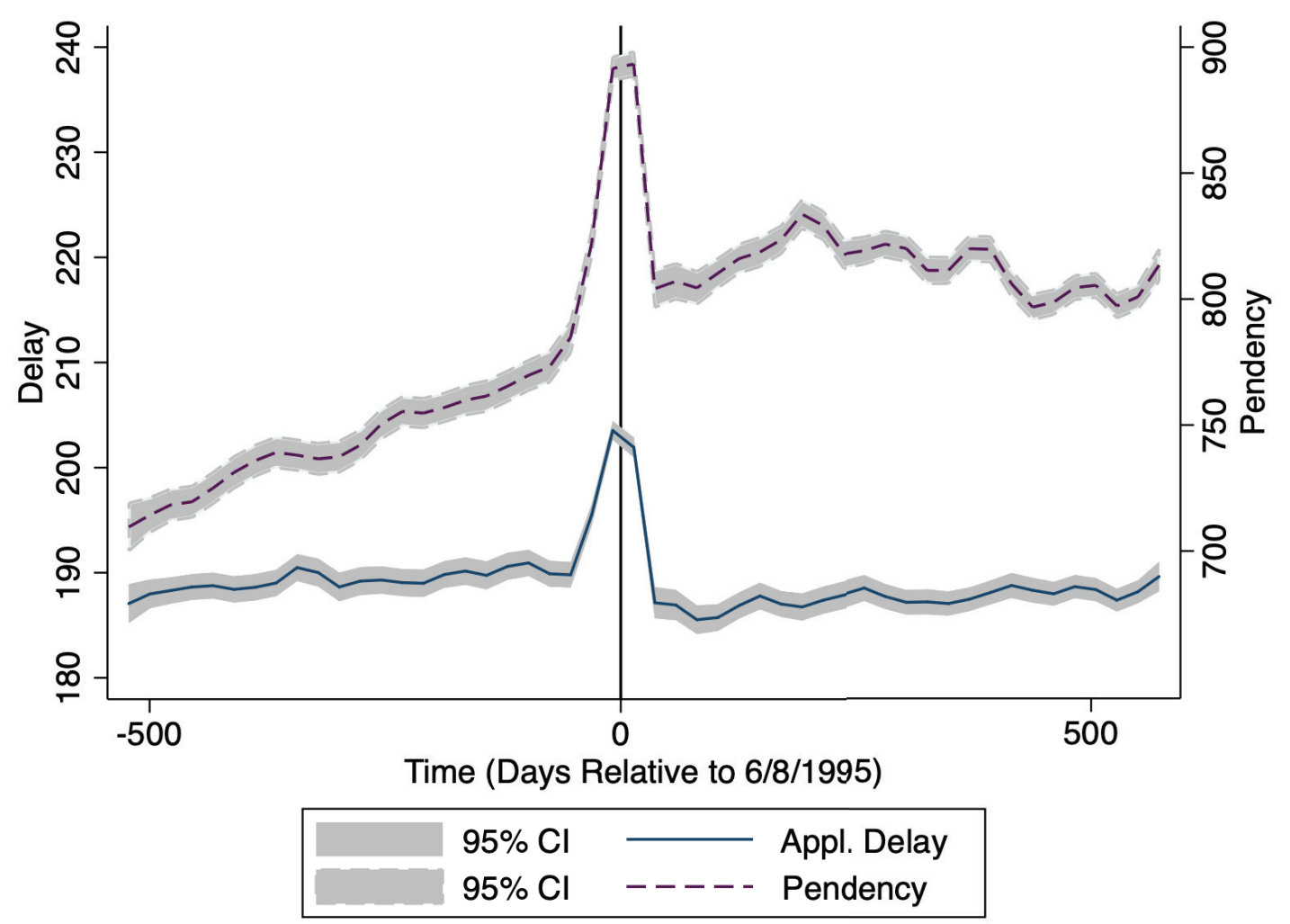

Notes: This graph shows how application pendency (i.e., total amount of time application was pending at the USPTO from filing to issuance) and applicant delay (i.e., time to respond to first non-final office action rejection plus the time taken to pay the issue fee) changed from January 1 , 1994, through December 31, 1996. The left y-axis is in days of applicant delay; the right y-axis is in days of pendency. "0" represents June 8, 1995, when the new TRIPS regime went into effect. The gray area around each line represents $95 \%$ confidence interval bands. The local polynomial regressions use an Epanechnikov kernel of degree 0 and bandwidth of 14 . 
Figure 4: Applicant Delay by Category

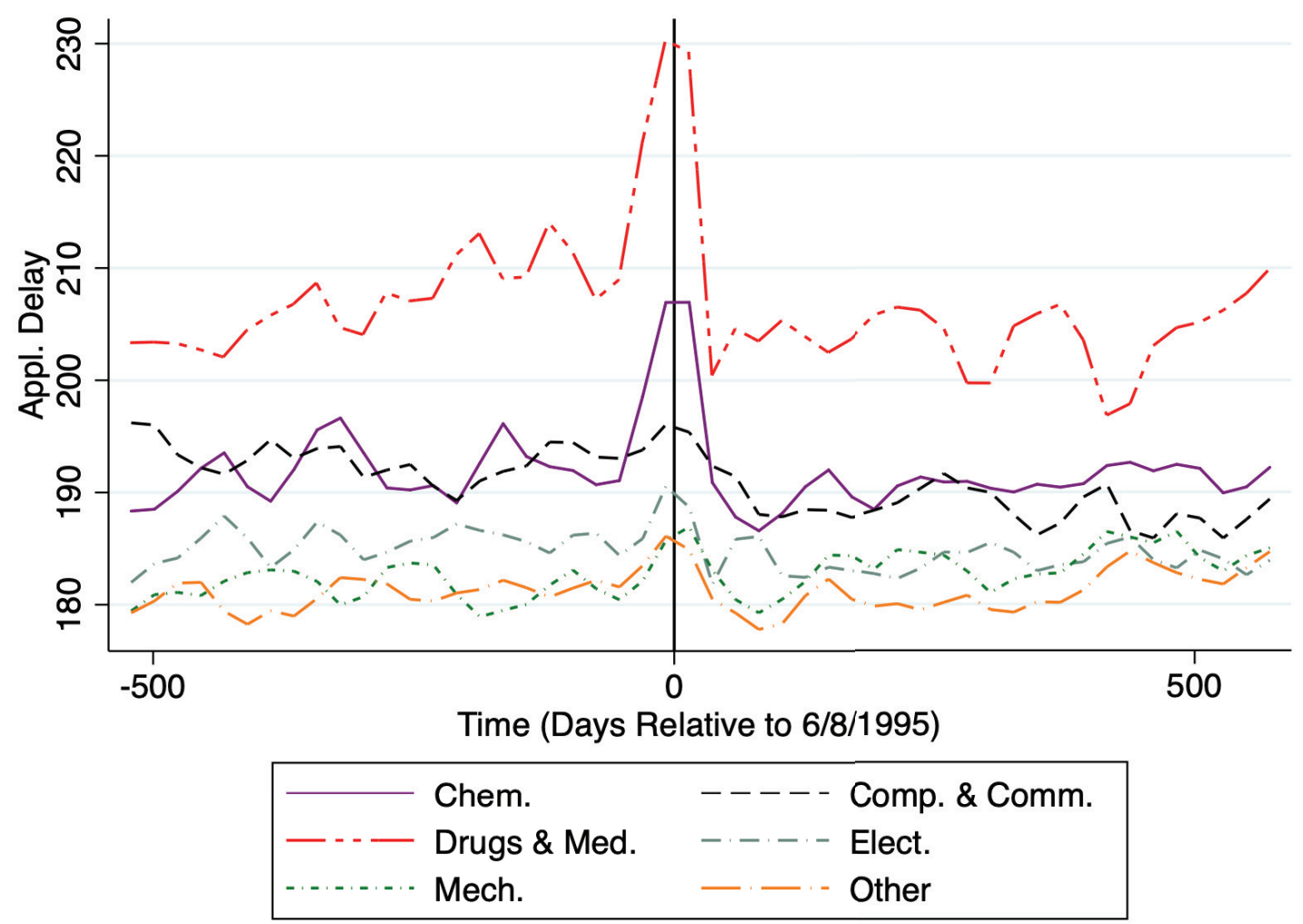

Notes: This graph shows how applicant delay (i.e., time to respond to first non-final office action rejection plus the time taken to pay the issue fee) changed for technologies broken down by NBER category from January 1, 1994, through December 31, 1996. The local polynomial regression is conducted using an Epanechnikov kernel of degree 0 and bandwidth of 14. "0" represents June 8, 1995, when the new TRIPS regime went into effect. 
Figure 5: Cross-Industry Differences in Applicant Delay (Post-TRIPS Coefficient)

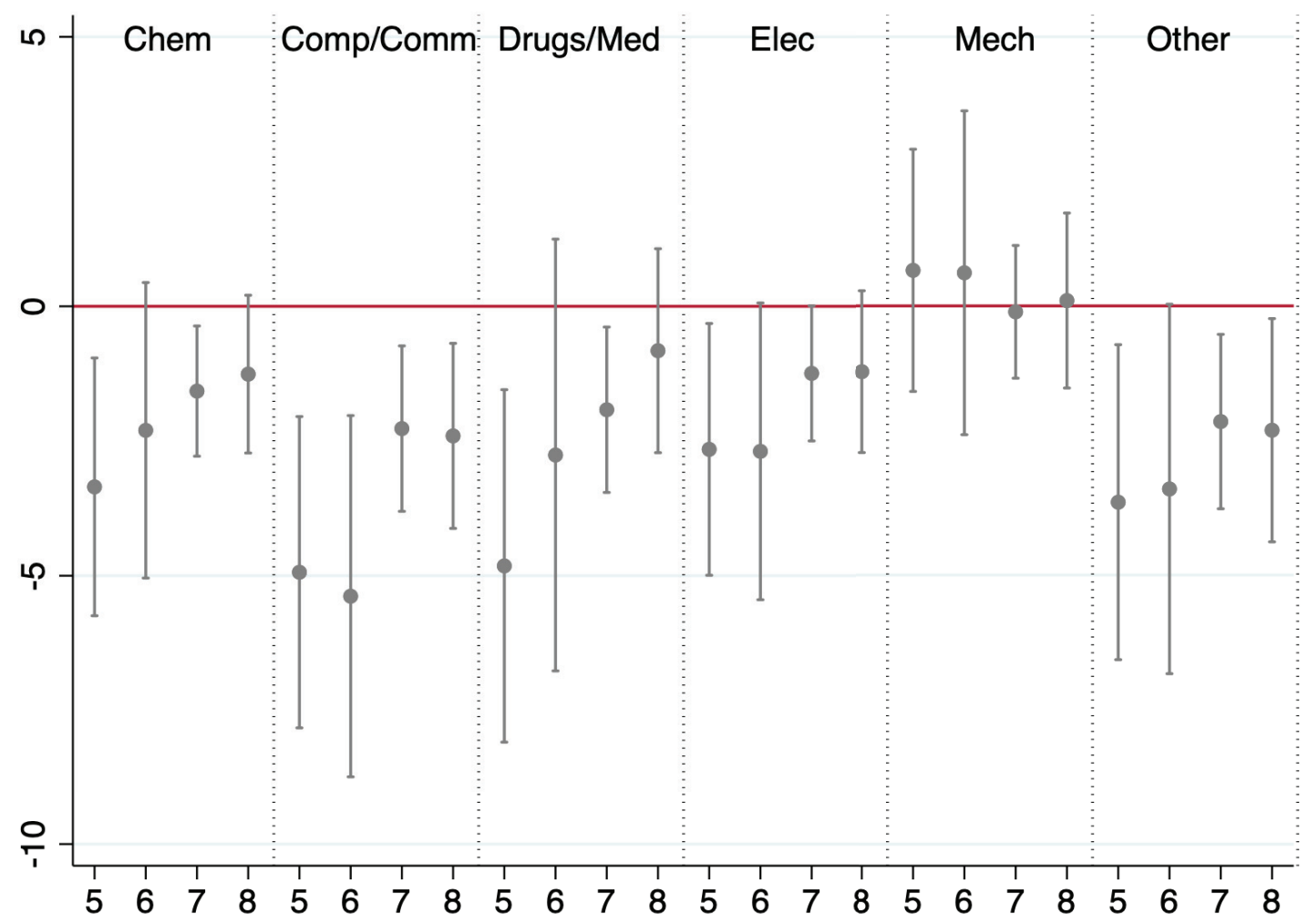

Notes: This graph shows category-level coefficients with standard error bars for the Post-TRIPS dummy variable from specifications in columns (5), (6), (7) and (8) of Table 2. The dependent variable is applicant delay for entries marked 5 and 6 and log applicant delay for entries marked 7 and 8 (both the coefficient and the error bands have been multiplied by 100 for the log specifications). 


\section{Figure 6: Number of Applications Filed by NBER Category}

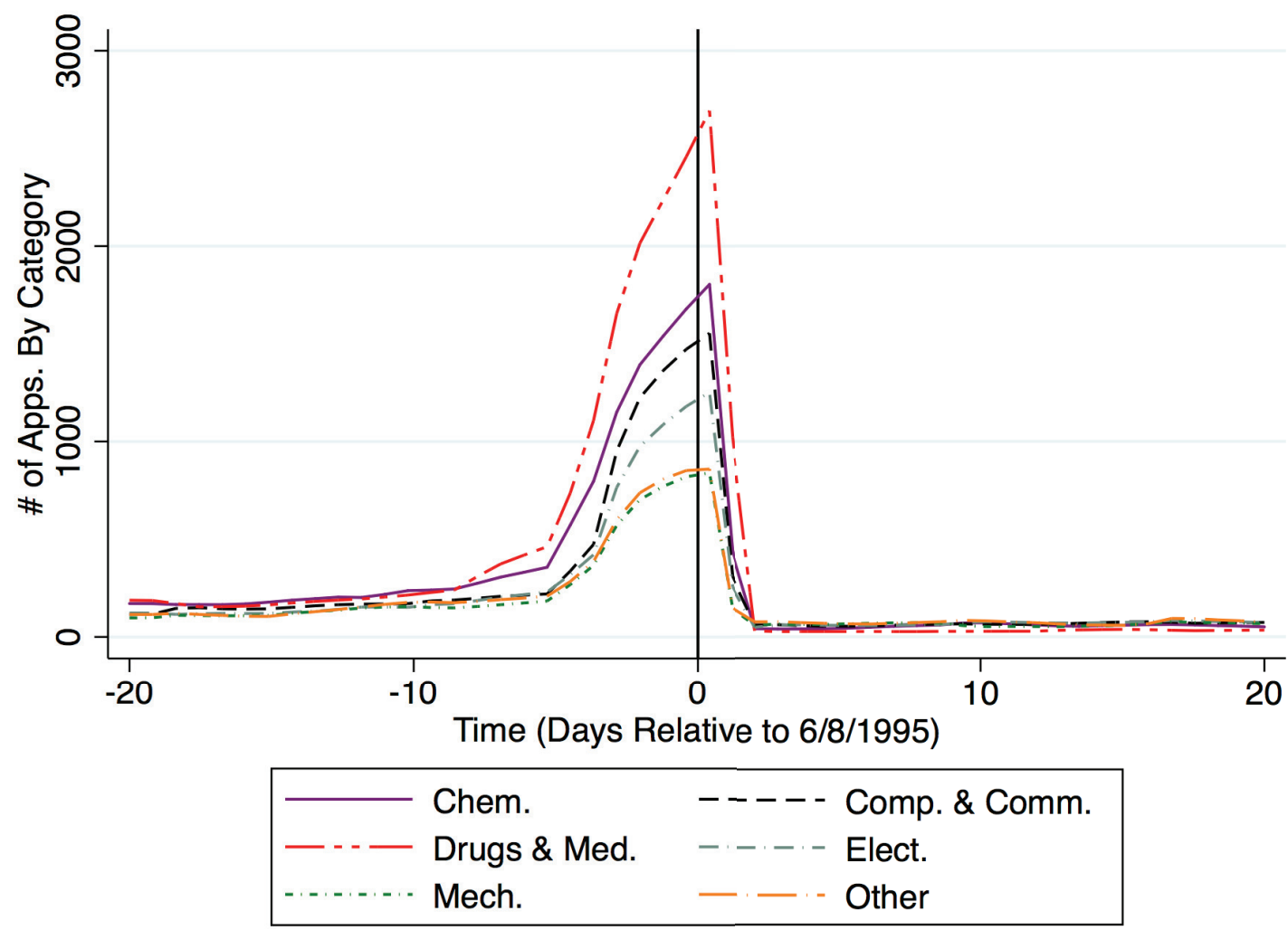

Notes: This graph shows a local polynomial regression of the number of patent applications filed per day by NBER category around the passage of TRIPS. The regression uses an Epanechnikov kernel of degree 0 and bandwidth of 1 , centered on June 8, 1995. 
Figure 7: Post-TRIPS Coefficient v. Percent Maintained by NBER Subcategory

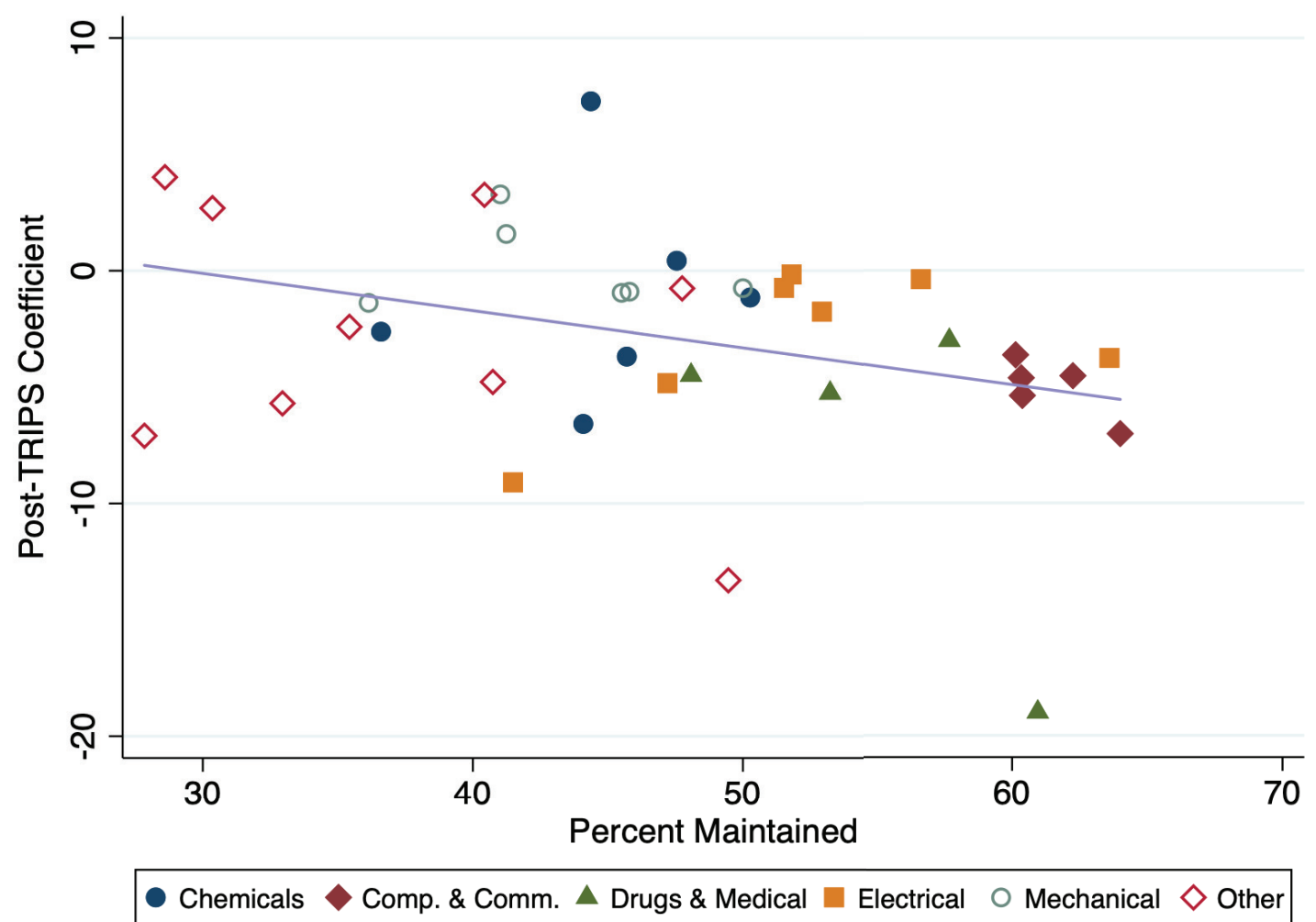

Notes: This scatterplot plots by NBER category the post-TRIPS coefficient calculated using the specification in col. (5) of Table 2 versus the percent of patents maintained through $111 / 2$ years for patent applications filed in 1994-1996. 
Figure 8: Patent Premiums in Arora et al. 2008 v. Post-TRIPS Coefficient

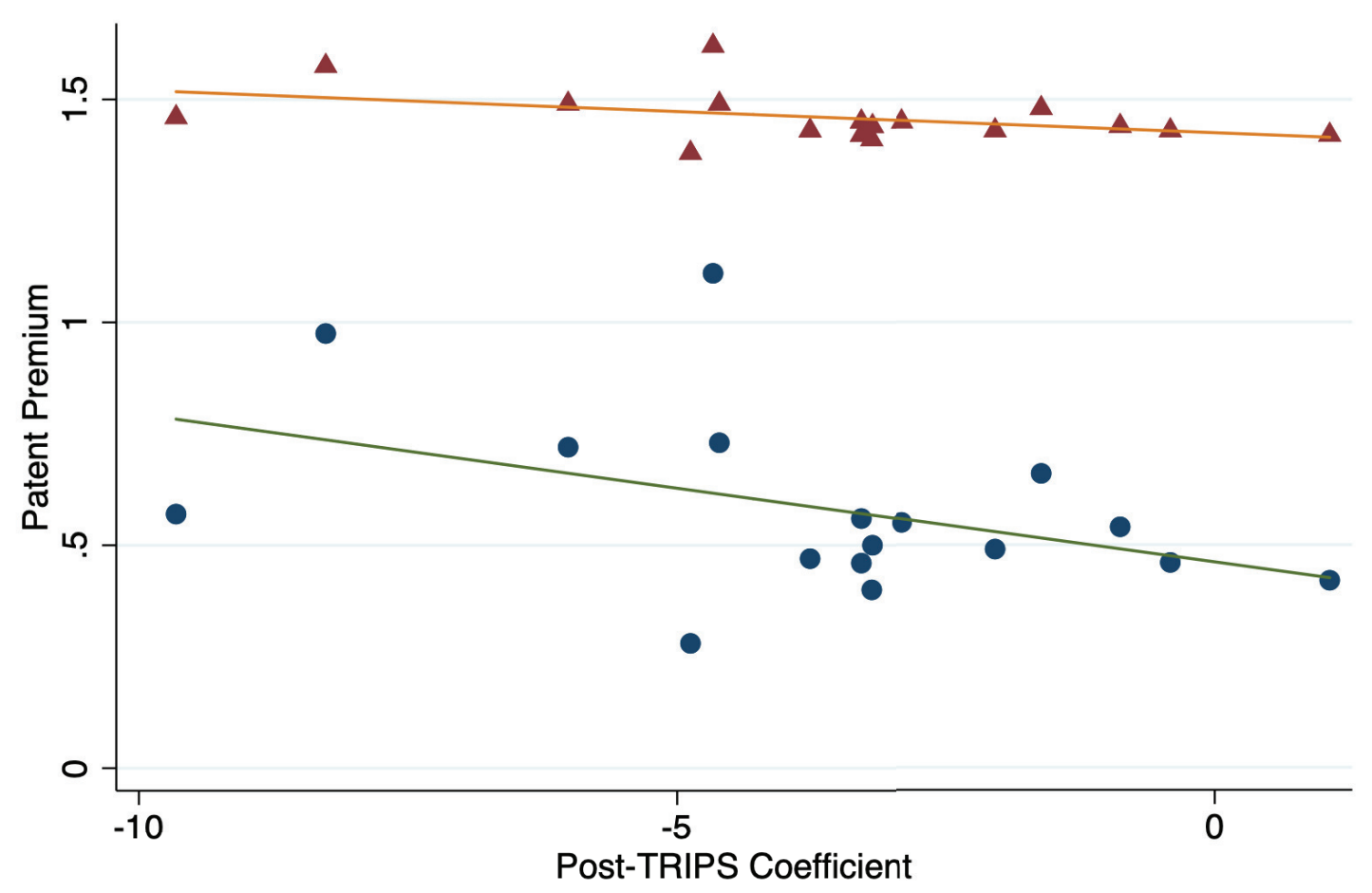

Unconditional Premium $\Delta$ Conditional Premium

Notes: This scatterplot plots the Expected Patent Premium and Conditional Patent Premium from Arora et al. 2008 table 7 versus the post-TRIPS coefficient calculated using the specification in col. (5) of Table 2. The main text describes the cross-walks and procedures used to connect the two types of data. 


\section{Tables}

Table 1: Summary Statistics

\begin{tabular}{|c|c|c|c|c|c|c|c|}
\hline & \multicolumn{2}{|c|}{1994} & \multicolumn{2}{|c|}{1995} & \multicolumn{2}{|c|}{1996} & All \\
\hline & 01/01-06/08 & 06/09-12/31 & 01/01-06/08 & $06 / 09-12 / 31$ & 01/01-06/08 & $06 / 09-12 / 31$ & 1994-1996 \\
\hline \# OAs & $\begin{array}{c}0.98 \\
(068)\end{array}$ & $\begin{array}{c}0.97 \\
(068)\end{array}$ & $\begin{array}{c}1.01 \\
(072)\end{array}$ & $\begin{array}{c}0.95 \\
(0.69)\end{array}$ & $\begin{array}{c}0.96 \\
(0.71)\end{array}$ & $\begin{array}{c}0.97 \\
(074)\end{array}$ & $\begin{array}{c}0.98 \\
(071)\end{array}$ \\
\hline \# Restricts. & $\begin{array}{c}0.11 \\
(0.33)\end{array}$ & $\begin{array}{c}0.11 \\
(0.33)\end{array}$ & $\begin{array}{c}0.12 \\
(0.35)\end{array}$ & $\begin{array}{c}0.11 \\
(0.33)\end{array}$ & $\begin{array}{c}0.11 \\
(0.33)\end{array}$ & $\begin{array}{c}0.11 \\
(0.32)\end{array}$ & $\begin{array}{c}0.11 \\
(0.33)\end{array}$ \\
\hline Small Entity & $\begin{array}{c}0.28 \\
(0.45)\end{array}$ & $\begin{array}{c}0.26 \\
(0.44)\end{array}$ & $\begin{array}{c}0.24 \\
(0.43)\end{array}$ & $\begin{array}{c}0.25 \\
(0.43)\end{array}$ & $\begin{array}{c}0.25 \\
(0.43)\end{array}$ & $\begin{array}{c}0.24 \\
(0.43)\end{array}$ & $\begin{array}{c}0.25 \\
(0.43)\end{array}$ \\
\hline Pro Se & $\begin{array}{c}0.05 \\
(0.21)\end{array}$ & $\begin{array}{c}0.04 \\
(0.21)\end{array}$ & $\begin{array}{c}0.05 \\
(0.22)\end{array}$ & $\begin{array}{c}0.05 \\
(0.21)\end{array}$ & $\begin{array}{c}0.05 \\
(0.21)\end{array}$ & $\begin{array}{c}0.05 \\
(0.21)\end{array}$ & $\begin{array}{c}0.05 \\
(0.21)\end{array}$ \\
\hline Remainder & $\begin{array}{c}538.37 \\
(365.30)\end{array}$ & $\begin{array}{c}560.66 \\
(354.79)\end{array}$ & $\begin{array}{c}628.02 \\
(398.15)\end{array}$ & $\begin{array}{c}632.97 \\
(330.77)\end{array}$ & $\begin{array}{c}634.35 \\
(318.31)\end{array}$ & $\begin{array}{c}620.14 \\
(310.91)\end{array}$ & $\begin{array}{c}605.12 \\
(349.50)\end{array}$ \\
\hline U.S. Patentee & $\begin{array}{c}0.55 \\
(0.50)\end{array}$ & $\begin{array}{c}0.53 \\
(0.50)\end{array}$ & $\begin{array}{c}0.59 \\
(0.49)\end{array}$ & $\begin{array}{c}0.52 \\
(0.50)\end{array}$ & $\begin{array}{c}0.53 \\
(0.50)\end{array}$ & $\begin{array}{c}0.53 \\
(0.50)\end{array}$ & $\begin{array}{c}0.54 \\
(0.50)\end{array}$ \\
\hline \# Claims & $\begin{array}{c}14.23 \\
(11.74)\end{array}$ & $\begin{array}{c}14.46 \\
(11.55)\end{array}$ & $\begin{array}{c}15.22 \\
(13.55)\end{array}$ & $\begin{array}{c}14.99 \\
(11.89)\end{array}$ & $\begin{array}{c}15.51 \\
(12.26)\end{array}$ & $\begin{array}{c}15.68 \\
(12.46)\end{array}$ & $\begin{array}{c}15.06 \\
(12.33)\end{array}$ \\
\hline \# Citations & $\begin{array}{c}10.48 \\
(16.25)\end{array}$ & $\begin{array}{c}10.20 \\
(16.32)\end{array}$ & $\begin{array}{c}9.37 \\
(14.97)\end{array}$ & $\begin{array}{c}9.12 \\
(14.53)\end{array}$ & $\begin{array}{c}8.80 \\
(13.93)\end{array}$ & $\begin{array}{c}8.38 \\
(13.19)\end{array}$ & $\begin{array}{c}9.32 \\
(14.84)\end{array}$ \\
\hline Continuation & $\begin{array}{c}0.15 \\
(0.36)\end{array}$ & $\begin{array}{c}0.15 \\
(0.36)\end{array}$ & $\begin{array}{c}0.18 \\
(0.39)\end{array}$ & $\begin{array}{c}0.10 \\
(0.30)\end{array}$ & $\begin{array}{c}0.11 \\
(0.31)\end{array}$ & $\begin{array}{c}0.11 \\
(0.32)\end{array}$ & $\begin{array}{c}0.13 \\
(0.34)\end{array}$ \\
\hline Divisional & $\begin{array}{c}0.06 \\
(0.24)\end{array}$ & $\begin{array}{c}0.06 \\
(0.24)\end{array}$ & $\begin{array}{c}0.15 \\
(0.36)\end{array}$ & $\begin{array}{c}0.05 \\
(0.21)\end{array}$ & $\begin{array}{c}0.05 \\
(0.23)\end{array}$ & $\begin{array}{c}0.06 \\
(0.23)\end{array}$ & $\begin{array}{c}0.07 \\
(0.26)\end{array}$ \\
\hline Nat'l Stage & $\begin{array}{c}0.05 \\
(0.21)\end{array}$ & $\begin{array}{c}0.05 \\
(0.22)\end{array}$ & $\begin{array}{c}0.04 \\
(0.21)\end{array}$ & $\begin{array}{c}0.06 \\
(0.24)\end{array}$ & $\begin{array}{c}0.07 \\
(0.25)\end{array}$ & $\begin{array}{c}0.07 \\
(0.25)\end{array}$ & $\begin{array}{c}0.06 \\
(0.23)\end{array}$ \\
\hline Provisional & $\begin{array}{c}0.00 \\
(0.00)\end{array}$ & $\begin{array}{c}0.00 \\
(0.00)\end{array}$ & $\begin{array}{c}0.00 \\
(0.00)\end{array}$ & $\begin{array}{c}0.00 \\
(0.04)\end{array}$ & $\begin{array}{c}0.01 \\
(0.09)\end{array}$ & $\begin{array}{c}0.04 \\
(0.19)\end{array}$ & $\begin{array}{c}0.01 \\
(0.10)\end{array}$ \\
\hline Appealed & $\begin{array}{c}0.03 \\
(0.17)\end{array}$ & $\begin{array}{c}0.03 \\
(0.17)\end{array}$ & $\begin{array}{c}0.05 \\
(0.23)\end{array}$ & $\begin{array}{c}0.05 \\
(0.21)\end{array}$ & $\begin{array}{c}0.07 \\
(0.25)\end{array}$ & $\begin{array}{c}0.09 \\
(0.29)\end{array}$ & $\begin{array}{c}0.06 \\
(0.23)\end{array}$ \\
\hline App. Delay & $\begin{array}{l}188.42 \\
(74.00)\end{array}$ & $\begin{array}{l}189.57 \\
(80.18)\end{array}$ & $\begin{array}{l}196.49 \\
(81.29)\end{array}$ & $\begin{array}{l}186.64 \\
(74.68)\end{array}$ & $\begin{array}{l}187.52 \\
(74.78)\end{array}$ & $\begin{array}{l}188.17 \\
(73.92)\end{array}$ & $\begin{array}{l}189.75 \\
(76.88)\end{array}$ \\
\hline Ln. App. Delay & $\begin{array}{c}5.18 \\
(0.36)\end{array}$ & $\begin{array}{c}5.18 \\
(0.36)\end{array}$ & $\begin{array}{c}5.21 \\
(0.37)\end{array}$ & $\begin{array}{c}5.16 \\
(0.37)\end{array}$ & $\begin{array}{c}5.17 \\
(0.37)\end{array}$ & $\begin{array}{c}5.18 \\
(0.36)\end{array}$ & $\begin{array}{c}5.18 \\
(0.37)\end{array}$ \\
\hline Pendency & $\begin{array}{c}725.06 \\
(416.11)\end{array}$ & $\begin{array}{c}747.75 \\
(405.80)\end{array}$ & $\begin{array}{c}826.37 \\
(461.55)\end{array}$ & $\begin{array}{c}814.43 \\
(384.40)\end{array}$ & $\begin{array}{c}817.96 \\
(372.99)\end{array}$ & $\begin{array}{c}805.49 \\
(368.18)\end{array}$ & $\begin{array}{c}792.59 \\
(404.89)\end{array}$ \\
\hline \# Extensions & $\begin{array}{c}0.57 \\
(0.95)\end{array}$ & $\begin{array}{c}0.56 \\
(0.95)\end{array}$ & $\begin{array}{c}0.72 \\
(1.17)\end{array}$ & $\begin{array}{c}0.54 \\
(0.96)\end{array}$ & $\begin{array}{c}0.58 \\
(1.00)\end{array}$ & $\begin{array}{c}0.60 \\
(1.04)\end{array}$ & $\begin{array}{c}0.60 \\
(1.03)\end{array}$ \\
\hline Extended? & $\begin{array}{c}0.38 \\
(0.49)\end{array}$ & $\begin{array}{c}0.38 \\
(0.48)\end{array}$ & $\begin{array}{c}0.43 \\
(0.49)\end{array}$ & $\begin{array}{c}0.36 \\
(0.48)\end{array}$ & $\begin{array}{c}0.37 \\
(0.48)\end{array}$ & $\begin{array}{c}0.38 \\
(0.49)\end{array}$ & $\begin{array}{c}0.38 \\
(0.49)\end{array}$ \\
\hline Non-Final OA Delay & $\begin{array}{l}108.29 \\
(98.32)\end{array}$ & $\begin{array}{c}109.25 \\
(101.76)\end{array}$ & $\begin{array}{c}119.94 \\
(114.85)\end{array}$ & $\begin{array}{l}105.46 \\
(97.97)\end{array}$ & $\begin{array}{c}107.48 \\
(101.54)\end{array}$ & $\begin{array}{c}108.53 \\
(102.79)\end{array}$ & $\begin{array}{c}110.19 \\
(103.73)\end{array}$ \\
\hline $\begin{array}{l}\text { Issue Fee Delay } \\
\text { Observations }\end{array}$ & $\begin{array}{c}78.40 \\
(48.14) \\
49,503\end{array}$ & $\begin{array}{c}77.84 \\
(49.14) \\
72,681\end{array}$ & $\begin{array}{c}78.41 \\
(49.01) \\
78,278\end{array}$ & $\begin{array}{c}75.99 \\
(49.12) \\
64,277\end{array}$ & $\begin{array}{l}76.13 \\
(47.59) \\
56,806\end{array}$ & $\begin{array}{c}76.82 \\
(46.67) \\
86,162\end{array}$ & $\begin{array}{l}77.27 \\
(48.27) \\
407,707\end{array}$ \\
\hline
\end{tabular}

Notes: This table shows summary statistics for various patent characteristics for six different time periods in our dataset: January 1 through June 7, and June 8 through December 31, for 1994, 1995, and 1996. The characteristics summarized include: the average number of non-final office actions and restriction requirements issued by the patent office; the probability that an applicant was a small entity or was proceeding pro se; the average number of patent claims; the average number of backward citations to patents from other patents issued up through 2006; the probability an application claimed priority to another patent application as a continuation, divisional, national stage, or provisional application; the probability that an applicant appealed an adverse decision by the patent office; the probability that the applicant sought an extension when responding to a non-final office action and the average number of extensions sought; and variables related to applicant delay and pendency. Standard deviations are in ( ). 


\section{Table 2: Effect of TRIPS on Applicant Delay and Log Applicant Delay}

\begin{tabular}{|c|c|c|c|c|c|c|c|c|}
\hline & $\begin{array}{c}\text { Delay } \\
(1)\end{array}$ & $\begin{array}{c}\text { Delay } \\
(2)\end{array}$ & $\begin{array}{c}\text { Log Delay } \\
(3)\end{array}$ & $\begin{array}{c}\text { Log Delay } \\
(4)\end{array}$ & $\begin{array}{c}\text { Delay } \\
(5)\end{array}$ & $\begin{array}{c}\text { Delay } \\
(6)\end{array}$ & $\begin{array}{c}\text { Log Delay } \\
(7)\end{array}$ & $\begin{array}{c}\text { Log Delay } \\
(8)\end{array}$ \\
\hline Post-TRIPS & $\begin{array}{l}-8.034^{* * *} \\
(0.271)\end{array}$ & $\begin{array}{l}-8.685^{* * *} \\
(0.302)\end{array}$ & $\begin{array}{l}-4.213^{* * *} \\
(0.131)\end{array}$ & $\begin{array}{l}-4.615^{* * *} \\
(0.144)\end{array}$ & $\begin{array}{l}-3.316^{* * *} \\
(0.686)\end{array}$ & $\begin{array}{l}-2.966^{* * *} \\
(0.809)\end{array}$ & $\begin{array}{l}-1.636^{* * *} \\
(0.378)\end{array}$ & $\begin{array}{l}-1.463^{* * *} \\
(0.443)\end{array}$ \\
\hline \# OAs & - & - & - & - & $\begin{array}{l}-0.947^{* *} \\
(0.422)\end{array}$ & $\begin{array}{l}-0.939^{* *} \\
(0.454)\end{array}$ & $\begin{array}{l}-0.241 \\
(0.188)\end{array}$ & $\begin{array}{l}-0.256 \\
(0.200)\end{array}$ \\
\hline \# Restricts. & - & - & - & - & $\begin{array}{l}2.429^{* * *} \\
(0.523)\end{array}$ & $\begin{array}{l}2.850^{* * *} \\
(0.608)\end{array}$ & $\begin{array}{l}1.238^{* * *} \\
(0.232)\end{array}$ & $\begin{array}{l}1.385^{* * *} \\
(0.268)\end{array}$ \\
\hline Small Entity & - & - & - & - & $\begin{array}{c}2.054 \\
(1.300)\end{array}$ & $\begin{array}{c}2.526^{*} \\
(1.455)\end{array}$ & $\begin{array}{l}1.712^{* * *} \\
(0.603)\end{array}$ & $\begin{array}{l}1.991^{* * *} \\
(0.708)\end{array}$ \\
\hline Remainder & - & - & - & - & $\begin{array}{l}0.005^{* * *} \\
(0.001)\end{array}$ & $\begin{array}{l}0.005^{* * *} \\
(0.001)\end{array}$ & $\begin{array}{l}0.004^{* * *} \\
(0.000)\end{array}$ & $\begin{array}{l}0.004^{* * *} \\
(0.000)\end{array}$ \\
\hline U.S. Patentee & - & - & - & - & $\begin{array}{c}3.524 \\
(6.331)\end{array}$ & $\begin{array}{l}-0.490 \\
(6.362)\end{array}$ & $\begin{array}{l}-0.699 \\
(2.661)\end{array}$ & $\begin{array}{l}-2.217 \\
(2.927)\end{array}$ \\
\hline \# Claims & - & - & - & - & $\begin{array}{l}0.148^{* * *} \\
(0.021)\end{array}$ & $\begin{array}{l}0.157^{* * *} \\
(0.025)\end{array}$ & $\begin{array}{l}0.068^{* * *} \\
(0.011)\end{array}$ & $\begin{array}{l}0.072^{* * *} \\
(0.012)\end{array}$ \\
\hline \# Citations & - & - & - & - & $\begin{array}{l}-0.133^{* * *} \\
(0.016)\end{array}$ & $\begin{array}{l}-0.132^{* * *} \\
(0.017)\end{array}$ & $\begin{array}{l}-0.053^{* * *} \\
(0.008)\end{array}$ & $\begin{array}{l}-0.053^{* * *} \\
(0.009)\end{array}$ \\
\hline Continuation & - & - & - & - & $\begin{array}{l}4.113^{* * *} \\
(0.683)\end{array}$ & $\begin{array}{l}4.699^{* * *} \\
(0.754)\end{array}$ & $\begin{array}{l}1.880^{* * *} \\
(0.342)\end{array}$ & $\begin{array}{l}2.237^{* * *} \\
(0.381)\end{array}$ \\
\hline Divisional & - & - & - & - & $\begin{array}{l}-2.172^{* * *} \\
(0.741)\end{array}$ & $\begin{array}{l}-1.401^{*} \\
(0.792)\end{array}$ & $\begin{array}{l}-1.550^{* * *} \\
(0.352)\end{array}$ & $\begin{array}{l}-1.187^{* * *} \\
(0.381)\end{array}$ \\
\hline Nat'l Stage & - & - & - & - & $\begin{array}{l}4.689^{* * *} \\
(1.100)\end{array}$ & $\begin{array}{l}5.835^{* * *} \\
(1.299)\end{array}$ & $\begin{array}{l}2.550^{* * *} \\
(0.490)\end{array}$ & $\begin{array}{l}3.109^{* * *} \\
(0.583)\end{array}$ \\
\hline Provisional & - & - & - & - & $\begin{array}{c}3.133 \\
(1.959)\end{array}$ & $\begin{array}{c}3.768^{*} \\
(2.254)\end{array}$ & $\begin{array}{l}3.107^{* * *} \\
(0.917)\end{array}$ & $\begin{array}{l}3.476^{* * *} \\
(1.059)\end{array}$ \\
\hline Appealed & - & - & - & - & $\begin{array}{l}16.392^{* * *} \\
(1.495)\end{array}$ & $\begin{array}{l}15.414^{* * *} \\
(1.540)\end{array}$ & $\begin{array}{l}7.177^{* * *} \\
(0.651)\end{array}$ & $\begin{array}{l}6.910^{* * *} \\
(0.680)\end{array}$ \\
\hline Constant & $\begin{array}{c}193.070^{* * *} \\
(0.181)\end{array}$ & $\begin{array}{c}193.687^{* * *} \\
(0.216)\end{array}$ & $\begin{array}{c}519.892^{* * *} \\
(0.084)\end{array}$ & $\begin{array}{c}520.296^{* * *} \\
(0.099)\end{array}$ & $\begin{array}{l}198.534^{* * *} \\
(11.132)\end{array}$ & $\begin{array}{l}205.056^{* * *} \\
(13.179)\end{array}$ & $\begin{array}{c}520.538^{* * *} \\
(4.786)\end{array}$ & $\begin{array}{c}523.392^{* * *} \\
(5.316)\end{array}$ \\
\hline Years & 1994-96 & $\begin{array}{l}\text { No inner } \\
\text { window }\end{array}$ & 1994-96 & $\begin{array}{l}\text { No inner } \\
\text { window }\end{array}$ & 1994-96 & $\begin{array}{l}\text { No inner } \\
\text { window }\end{array}$ & 1994-96 & $\begin{array}{l}\text { No inner } \\
\text { window }\end{array}$ \\
\hline Fixed Eff. & No & No & Yes & Yes & No & No & Yes & Yes \\
\hline Adj. R-sq. & 0.003 & 0.003 & 0.003 & 0.004 & 0.172 & 0.170 & 0.268 & 0.265 \\
\hline Obs. & 323,256 & 254,454 & 323,256 & 254,454 & 265,639 & 209,766 & 265,639 & 209,766 \\
\hline
\end{tabular}

Notes: Dependent variable is applicant delay in cols. (1), (2), (5) and (6), which is the sum of the time that an applicant took to respond to a first non-final rejection plus the time between when the notice of allowance was mailed and the issue fee was paid. Dependent variable is log applicant delay in cols. (3), (4), (7), and (8), and coefficients and standard errors are multiplied by 100 in those columns. Robust standard errors in cols. (1)-(4); clustered standard errors at patent assignee level in cols. (5)-(8). Fixed effects are for patent assignee and patent class. Cols. (2), (4), (6), (8) exclude applications filed 12/8/94-8/8/95 (between date of TRIPS enactment to two months after TRIPS went into effect). Remainder $=$ amount of prosecution delay attributable to the patent office. All other variables are as described in the text. ${ }^{* * *}=$ significant at $1 \%$ level, ${ }^{* *}=$ significant at $5 \%$ level, ${ }^{*}=$ significant at $10 \%$ level. 
Table 3: Effect of TRIPS on Applicant Delay with Time Trend Corrections

\begin{tabular}{|c|c|c|c|}
\hline & $\begin{array}{c}\text { Delay } \\
(1)\end{array}$ & $\begin{array}{c}\text { Delay } \\
\text { (2) }\end{array}$ & $\begin{array}{c}\text { Delay } \\
\text { (3) }\end{array}$ \\
\hline Post-TRIPS & $\begin{array}{c}-11.806^{* * *} \\
(0.483)\end{array}$ & $\begin{array}{l}-1.552^{*} \\
(0.792)\end{array}$ & $\begin{array}{l}-1.458 \\
(1.099)\end{array}$ \\
\hline time*Post-TRIPS & $\begin{array}{l}-0.014^{* * *} \\
(0.001)\end{array}$ & $\begin{array}{l}-0.004^{*} \\
(0.002)\end{array}$ & $\begin{array}{l}-0.009 \\
(0.006)\end{array}$ \\
\hline time*time*Post-TRIPS & - & - & $\begin{array}{c}0.000^{*} \\
(0.000)\end{array}$ \\
\hline time & $\begin{array}{l}0.018^{* * *} \\
(0.001)\end{array}$ & $\begin{array}{l}-0.001 \\
(0.001)\end{array}$ & $\begin{array}{l}-0.002^{*} \\
(0.001)\end{array}$ \\
\hline time*time & - & - & $\begin{array}{l}-0.000^{* * *} \\
(0.000)\end{array}$ \\
\hline \# OAs & - & $\begin{array}{l}-1.028^{* *} \\
(0.408)\end{array}$ & $\begin{array}{l}-1.020^{* *} \\
(0.407)\end{array}$ \\
\hline \# Restricts. & - & $\begin{array}{l}2.353^{* * *} \\
(0.504)\end{array}$ & $\begin{array}{l}2.358^{* * *} \\
(0.504)\end{array}$ \\
\hline Small Entity & - & $\begin{array}{c}1.331 \\
(1.265)\end{array}$ & $\begin{array}{c}1.361 \\
(1.265)\end{array}$ \\
\hline Remainder & - & $\begin{array}{l}0.005^{* * *} \\
(0.001)\end{array}$ & $\begin{array}{l}0.005^{* * *} \\
(0.001)\end{array}$ \\
\hline U.S. Patentee & - & $\begin{array}{c}2.794 \\
(6.143)\end{array}$ & $\begin{array}{c}2.842 \\
(6.140)\end{array}$ \\
\hline \# Claims & - & $\begin{array}{l}0.149^{* * *} \\
(0.020)\end{array}$ & $\begin{array}{l}0.149^{* * *} \\
(0.020)\end{array}$ \\
\hline \# Citations & - & $\begin{array}{l}-0.134^{* * *} \\
(0.015)\end{array}$ & $\begin{array}{l}-0.135^{* * *} \\
(0.015)\end{array}$ \\
\hline Continuation & - & $\begin{array}{l}4.351^{* * *} \\
(0.685)\end{array}$ & $\begin{array}{l}4.629 * * * \\
(0.703)\end{array}$ \\
\hline Divisional & - & $\begin{array}{l}-1.977^{* * *} \\
(0.734)\end{array}$ & $\begin{array}{l}-1.919^{* * *} \\
(0.730)\end{array}$ \\
\hline Nat'l Stage & - & $\begin{array}{l}4.996^{* * *} \\
(1.107)\end{array}$ & $\begin{array}{l}5.316^{* * *} \\
(1.106)\end{array}$ \\
\hline Provisional & - & $\begin{array}{c}2.895 \\
(1.963)\end{array}$ & $\begin{array}{c}2.908 \\
(1.963)\end{array}$ \\
\hline Appealed & - & $\begin{array}{l}16.449^{* * *} \\
(1.455)\end{array}$ & $\begin{array}{l}16.506^{* * *} \\
(1.466)\end{array}$ \\
\hline Constant & $\begin{array}{c}195.662^{* * *} \\
(0.212)\end{array}$ & $\begin{array}{l}199.055^{* * *} \\
(11.069)\end{array}$ & $\begin{array}{l}199.590^{* * *} \\
(11.093)\end{array}$ \\
\hline Fixed Eff. & No & Yes & Yes \\
\hline Adj. R-squared & 0.005 & 0.172 & 0.172 \\
\hline F-Test & 718.68 & 6.73 & 4.84 \\
\hline Prob $>$ F & 0.0000 & 0.0012 & 0.0023 \\
\hline Observations & 323,256 & 273,443 & 273,443 \\
\hline
\end{tabular}

Notes: Dependent variable is applicant delay. Robust standard errors in ( ) in col. (1); clustered standard errors at patent assignee level in ( ) in cols. (2)-(3). Years: 1994-96. F-Test is for Post-TRIPS and its interactions with time. Fixed effects for patent assignee and patent class. ${ }^{* * *}=$ significant at $1 \%$ level, ${ }^{* *}=$ significant at $5 \%$ level, ${ }^{*}=$ significant at $10 \%$ level. 
Table 4: Effect of TRIPS on Applicant Requested Extensions

\begin{tabular}{|c|c|c|c|c|c|c|}
\hline & $\begin{array}{c}\text { \# Ext } \\
(1)\end{array}$ & $\begin{array}{c}\text { \# Ext } \\
(2)\end{array}$ & $\begin{array}{c}\text { \# Ext } \\
(3)\end{array}$ & $\begin{array}{r}\text { Ext? } \\
(4) \\
\end{array}$ & $\begin{array}{r}\text { Ext? } \\
(5) \\
\end{array}$ & $\begin{array}{r}\text { Ext? } \\
(6)\end{array}$ \\
\hline Post-TRIPS & $\begin{array}{l}-0.079^{* * *} \\
(0.003)\end{array}$ & $\begin{array}{l}-0.070^{* * *} \\
(0.006)\end{array}$ & $\begin{array}{l}-0.075^{* * *} \\
(0.008)\end{array}$ & $\begin{array}{l}-0.041^{* * *} \\
(0.001)\end{array}$ & $\begin{array}{l}-0.036^{* * *} \\
(0.002)\end{array}$ & $\begin{array}{l}-0.030^{* * *} \\
(0.002)\end{array}$ \\
\hline \# OAs & $\begin{array}{l}0.718^{* * *} \\
(0.004)\end{array}$ & $\begin{array}{l}0.422^{* * *} \\
(0.030)\end{array}$ & $\begin{array}{l}0.421^{* * *} \\
(0.033)\end{array}$ & $\begin{array}{l}0.288^{* * *} \\
(0.001)\end{array}$ & $\begin{array}{l}0.229^{* * *} \\
(0.001)\end{array}$ & $\begin{array}{l}0.221^{* * *} \\
(0.001)\end{array}$ \\
\hline \# Restricts. & $\begin{array}{l}0.318^{* * *} \\
(0.006)\end{array}$ & $\begin{array}{l}0.092^{* * *} \\
(0.010)\end{array}$ & $\begin{array}{l}0.091^{* * *} \\
(0.012)\end{array}$ & $\begin{array}{l}0.109^{* * *} \\
(0.002)\end{array}$ & $\begin{array}{l}0.061^{* * *} \\
(0.003)\end{array}$ & $\begin{array}{l}0.054^{* * *} \\
(0.003)\end{array}$ \\
\hline Small Entity & - & $\begin{array}{l}-0.012 \\
(0.013)\end{array}$ & $\begin{array}{l}-0.004 \\
(0.014)\end{array}$ & - & $\begin{array}{l}0.045^{* * *} \\
(0.002)\end{array}$ & $\begin{array}{l}0.031^{* * *} \\
(0.002)\end{array}$ \\
\hline Remainder & - & $\begin{array}{l}0.001^{* * *} \\
(0.000)\end{array}$ & $\begin{array}{l}0.001^{* * *} \\
(0.000)\end{array}$ & - & $\begin{array}{l}0.000^{* * *} \\
(0.000)\end{array}$ & $\begin{array}{l}0.000^{* * *} \\
(0.000)\end{array}$ \\
\hline U.S. Patentee & - & $\begin{array}{l}-0.039 \\
(0.080)\end{array}$ & $\begin{array}{l}-0.053 \\
(0.100)\end{array}$ & - & $\begin{array}{l}-0.098^{* * *} \\
(0.002)\end{array}$ & $\begin{array}{l}-0.108^{* * *} \\
(0.002)\end{array}$ \\
\hline \# Claims & - & $\begin{array}{c}0.000 \\
(0.000)\end{array}$ & $\begin{array}{l}-0.000 \\
(0.000)\end{array}$ & - & $\begin{array}{l}0.001^{* * *} \\
(0.000)\end{array}$ & $\begin{array}{l}0.001^{* * *} \\
(0.000)\end{array}$ \\
\hline \# Citations & - & $\begin{array}{c}0.000 \\
(0.000)\end{array}$ & $\begin{array}{c}0.000 \\
(0.000)\end{array}$ & - & $\begin{array}{l}0.000^{* *} \\
(0.000)\end{array}$ & $\begin{array}{l}0.000^{* * *} \\
(0.000)\end{array}$ \\
\hline Continuation & - & $\begin{array}{l}0.111^{* * *} \\
(0.007)\end{array}$ & $\begin{array}{l}0.111^{\text {*** }} \\
(0.007)\end{array}$ & - & $\begin{array}{l}0.090^{* * *} \\
(0.002)\end{array}$ & $\begin{array}{l}0.072^{\text {*** }} \\
(0.002)\end{array}$ \\
\hline Divisional & - & $\begin{array}{l}-0.015^{*} \\
(0.008)\end{array}$ & $\begin{array}{l}-0.021^{* *} \\
(0.009)\end{array}$ & - & $\begin{array}{l}0.019^{* * *} \\
(0.003)\end{array}$ & $\begin{array}{c}0.003 \\
(0.003)\end{array}$ \\
\hline Nat'l Stage & - & $\begin{array}{c}0.014 \\
(0.012)\end{array}$ & $\begin{array}{c}0.020 \\
(0.014)\end{array}$ & - & $\begin{array}{l}0.055^{* * *} \\
(0.004)\end{array}$ & $\begin{array}{l}0.032^{* * *} \\
(0.004)\end{array}$ \\
\hline Provisional & - & $\begin{array}{c}0.035 \\
(0.022)\end{array}$ & $\begin{array}{c}0.034 \\
(0.025)\end{array}$ & - & $\begin{array}{l}0.075^{* * *} \\
(0.009)\end{array}$ & $\begin{array}{l}0.052^{\text {*** }} \\
(0.009)\end{array}$ \\
\hline Appealed & - & $\begin{array}{l}1.221^{* * *} \\
(0.067)\end{array}$ & $\begin{array}{l}1.185^{* * *} \\
(0.072)\end{array}$ & - & $\begin{array}{l}0.261^{* * *} \\
(0.005)\end{array}$ & $\begin{array}{l}0.255^{* * *} \\
(0.005)\end{array}$ \\
\hline Constant & $\begin{array}{l}-0.104^{* * *} \\
(0.004)\end{array}$ & $\begin{array}{l}-0.365^{* * *} \\
(0.091)\end{array}$ & $\begin{array}{l}-0.382^{* * *} \\
(0.097)\end{array}$ & - & - & - \\
\hline Years & 1994-96 & 1994-96 & $\begin{array}{l}\text { No inner } \\
\text { window }\end{array}$ & 1994-96 & $\begin{array}{l}\text { No inner } \\
\text { window }\end{array}$ & $\begin{array}{l}\text { No inner } \\
\text { window }\end{array}$ \\
\hline Fixed Eff. & No & Yes & Yes & No & No & Yes \\
\hline R-sq. & 0.264 & 0.530 & 0.523 & 0.130 & 0.187 & 0.203 \\
\hline Obs. & 407,707 & 334,178 & 265,423 & 407,707 & 272,861 & 272,852 \\
\hline
\end{tabular}

Notes: OLS coefficients in cols. (1)-(3); dependent variable is number of extension requests. Marginal effects coefficients for logit in cols. (4)-(6); dependent variable is whether the applicant made an extension request. Robust standard errors in ( ) in col. (1); clustered standard errors in ( ) at patent assignee level in cols. (2) and (3). Fixed effects are for patent assignee and patent class in cols. (2) and (3), and class in col. (6). R-squared is Adjusted R-squared in cols. (1)-(3) and pseudo R-squared in cols. (4)-(6). Cols. (3), (5)-(6) exclude applications filed 12/8/94-8/8/95. *** = significant at $1 \%$ level, ${ }^{* *}=$ significant at $5 \%$ level, ${ }^{*}=$ significant at $10 \%$ level. 
Table 5: Effect of TRIPS on Non-Final Office Action Response Time, Issue Fee Payment Time, and Probability of Continuation

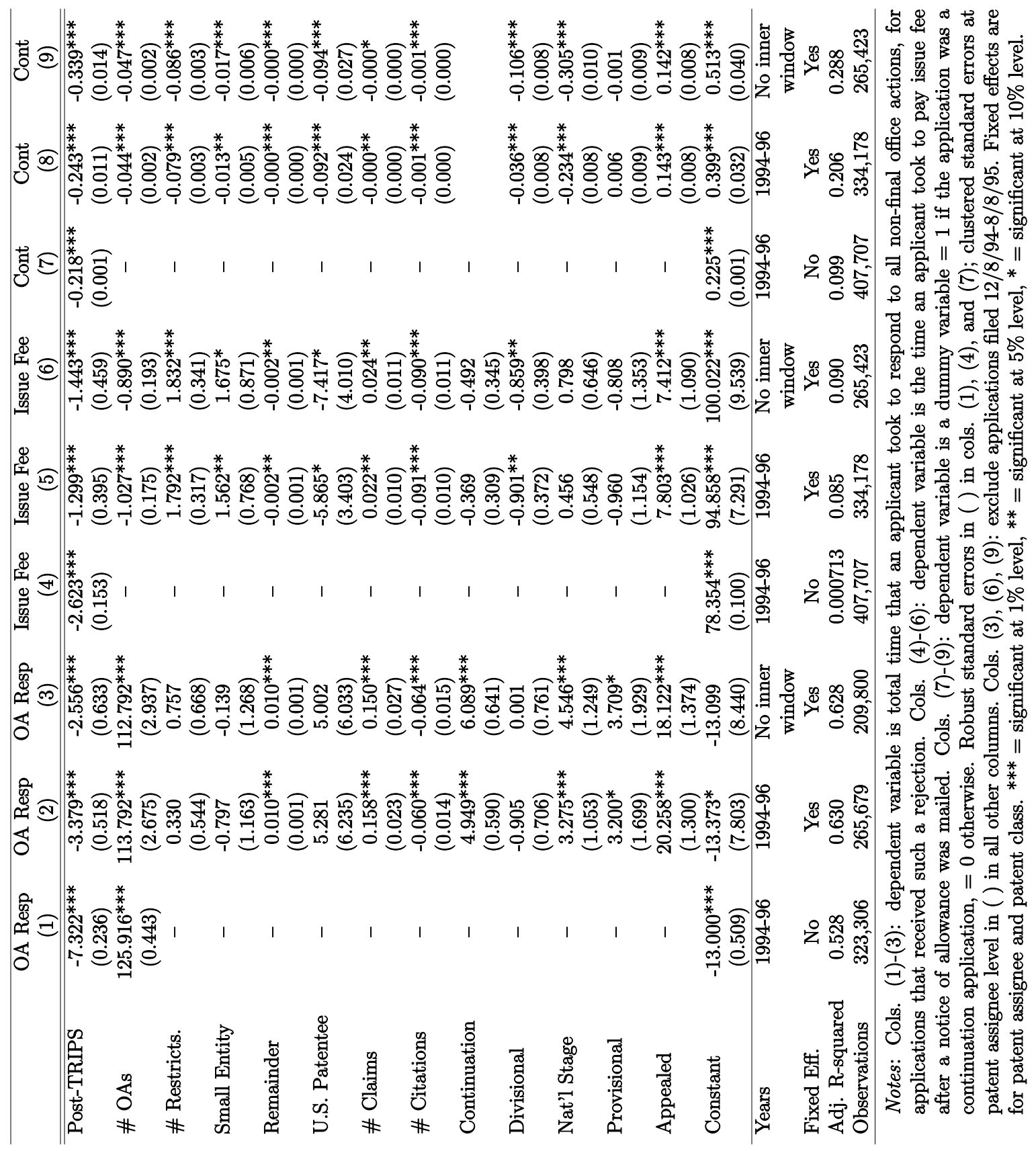


Table 6: Post-TRIPS Coefficient, \% Maintained, and Patent Count Selection Measure

\section{Across Subcategories}

\begin{tabular}{|c|c|c|c|c|c|c|}
\hline Subcategory & $\begin{array}{c}\text { Delay } \\
(5)\end{array}$ & $\begin{array}{c}\text { Delay } \\
(6)\end{array}$ & $\begin{array}{c}\text { Log Delay } \\
(7)\end{array}$ & $\begin{array}{c}\text { Log Delay } \\
(8)\end{array}$ & $\%$ Maint & Pat Ct \\
\hline \multicolumn{7}{|l|}{ Chemicals } \\
\hline Agric., Food, Textiles & $-2.62(7.63)$ & $-3.72(9.97)$ & $-3.04(3.19)$ & $-2.56(4.60)$ & 36.60 & 17.11 \\
\hline Coating & $0.43(4.58)$ & $7.20(5.29)$ & $1.05(1.98)$ & $3.10(2.79)$ & 47.55 & 10.35 \\
\hline Gas & $7.28(10.94)$ & $5.58(14.30)$ & $4.29(6.02)$ & $3.99(8.16)$ & 44.37 & 8.00 \\
\hline Organic Compounds & $-6.58(3.43)^{*}$ & $-4.26(3.77)$ & $-2.55(1.33)^{*}$ & $-1.90(1.57)$ & 44.09 & 13.86 \\
\hline Resins & $-1.15(2.58)$ & $-1.17(3.22)$ & $0.10(1.34)$ & $0.53(1.55)$ & 50.27 & 16.24 \\
\hline Chem.-Misc. & $-3.69(1.57)^{* *}$ & $-2.66(1.74)$ & $-2.14(0.79)^{* * *}$ & $-1.92(0.95)^{* *}$ & 45.70 & 7.96 \\
\hline \multicolumn{7}{|c|}{ Computers \& Communications } \\
\hline Communications & $-4.62(1.76)^{* * *}$ & $-4.53(1.99)^{* *}$ & $-2.86(0.91)^{* * *}$ & $-2.97(1.03)^{* * *}$ & 60.34 & 5.48 \\
\hline Comp. Hard. \& Software & $-5.38(1.83)^{* * *}$ & $-5.69(2.29)^{* *}$ & $-2.13(0.83)^{* *}$ & $-2.21(1.04)^{* *}$ & 60.38 & 8.45 \\
\hline Computer Peripherals & $-4.53(3.32)$ & $-6.43(4.22)$ & $-1.55(1.54)$ & $-2.07(2.01)$ & 62.25 & 7.62 \\
\hline Information Storage & $-3.63(2.82)$ & $-4.28(2.68)$ & $-1.62(1.47)$ & $-2.11(1.37)$ & 60.13 & 7.82 \\
\hline Elec. Bus. Meth. \& Soft. & $-7.02(6.31)$ & $-15.71(9.82)$ & $-4.11(2.19)^{*}$ & $-6.47(3.15)^{* *}$ & 64.00 & 8.44 \\
\hline \multicolumn{7}{|l|}{ Drugs \& Medical } \\
\hline Drugs & $-4.49(2.16)^{* *}$ & $-3.68(2.62)$ & $-1.74(0.89)^{*}$ & $-1.27(1.12)$ & 48.08 & 24.63 \\
\hline Surgery \& Med Inst. & $-3.01(2.83)$ & $-0.17(3.47)$ & $-0.57(1.57)$ & $1.47(2.01)$ & 57.68 & 9.13 \\
\hline Genetics & $-19.00(9.20)^{* *}$ & $-16.53(13.38)$ & $-10.08(4.04)^{* *}$ & $-9.90(6.47)$ & 60.95 & 29.83 \\
\hline Drugs and Med.-Misc. & $-5.26(9.14)$ & $-7.79(14.57)$ & $-2.93(3.93)$ & $-3.27(6.06)$ & 53.23 & 9.23 \\
\hline \multicolumn{7}{|l|}{ Electrical \& Electronics } \\
\hline Electrical Devices & $-0.74(1.74)$ & $-0.05(2.29)$ & $-0.63(1.09)$ & $-0.33(1.45)$ & 51.52 & 3.84 \\
\hline Electrical Lighting & $-9.09(3.53)^{* *}$ & $-5.71(3.98)$ & $-3.28(1.96)^{*}$ & $-1.92(2.23)$ & 41.49 & 5.85 \\
\hline Measuring and Testing & $-4.83(2.43)^{* *}$ & $-3.73(2.94)$ & $-3.00(1.38)^{* *}$ & $-3.37(1.71)^{* *}$ & 47.21 & 4.92 \\
\hline Nuclear \& X-rays & $-0.16(3.88)$ & $-0.73(4.53)$ & $-0.31(2.34)$ & $-0.71(2.74)$ & 51.80 & 5.76 \\
\hline Power Systems & $-1.76(1.71)$ & $-2.36(2.33)$ & $-0.97(0.98)$ & $-1.09(1.37)$ & 52.93 & 5.82 \\
\hline Semiconductor Devices & $-3.76(2.10)^{*}$ & $-3.88(2.31)^{*}$ & $-1.59(1.18)$ & $-1.72(1.35)$ & 63.60 & 8.40 \\
\hline Elec.-Misc. & $-0.38(3.33)$ & $-1.99(4.74)$ & $0.40(1.16)$ & $0.39(1.46)$ & 56.63 & 5.59 \\
\hline \multicolumn{7}{|l|}{ Mechanical } \\
\hline Mat. Proc. \& Handling & $1.58(2.63)$ & $2.67(3.26)$ & $0.66(1.38)$ & $0.61(1.70)$ & 41.24 & 6.16 \\
\hline Metal Working & $-0.90(3.42)$ & $-4.72(4.67)$ & $-1.78(1.82)$ & $-3.00(2.34)$ & 45.80 & 7.25 \\
\hline Motors \& Engines + Parts & $-0.95(2.50)$ & $0.53(3.31)$ & $-0.23(0.92)$ & $0.52(1.21)$ & 45.51 & 3.81 \\
\hline Optics & $-0.75(3.65)$ & $-1.25(5.21)$ & $-1.05(1.87)$ & $-0.87(2.69)$ & 50.00 & 4.88 \\
\hline Transportation & $-1.38(3.44)$ & $-0.11(4.96)$ & $-1.65(2.51)$ & $-0.86(3.64)$ & 36.14 & 3.71 \\
\hline Mech.-Misc. & $3.28(2.63)$ & $2.99(3.66)$ & $1.60(1.40)$ & $2.12(1.85)$ & 41.02 & 3.98 \\
\hline \multicolumn{7}{|l|}{ Others } \\
\hline Agric., Husbandry, Food & $-2.41(6.87)$ & $1.04(8.46)$ & $-2.05(3.45)$ & $-1.40(4.38)$ & 35.43 & 5.00 \\
\hline Amusement Devices & $4.02(10.85)$ & $2.67(12.51)$ & $0.71(4.44)$ & $0.97(6.32)$ & 28.60 & 3.75 \\
\hline Apparel \& Textile & $2.69(4.61)$ & $5.20(5.77)$ & $1.00(2.39)$ & $2.83(3.15)$ & 30.36 & 4.93 \\
\hline Earth Working \& Wells & $-13.30(13.12)$ & $-1.41(10.57)$ & $-5.38(7.17)$ & $-3.17(8.52)$ & 49.46 & 3.86 \\
\hline Furniture, House Fixtures & $-7.09(5.78)$ & $-7.38(7.72)$ & $-3.60(3.10)$ & $-3.86(4.04)$ & 27.84 & 3.48 \\
\hline Heating & $3.26(6.65)$ & $3.97(10.39)$ & $2.52(3.66)$ & $2.77(5.39)$ & 40.43 & 5.80 \\
\hline Pipes \& Joints & $-0.76(8.11)$ & $-2.68(10.49)$ & $-1.24(4.88)$ & $-2.17(6.18)$ & 47.75 & 5.07 \\
\hline Receptacles & $-5.70(4.54)$ & $-4.46(5.72)$ & $-4.29(3.05)$ & $-3.93(3.82)$ & 32.95 & 6.41 \\
\hline Other-Misc. & $-4.78(1.85)^{* * *}$ & $-5.66(2.41)^{* *}$ & $-2.12(1.06)^{* *}$ & $-2.68(1.35)^{* *}$ & 40.74 & 5.52 \\
\hline
\end{tabular}

Notes: Cols. (5) and (6) ((7) and (8)) are coefficients when applicant delay (log applicant delay) is regressed on a post-TRIPS dummy, as in specifications in the same-numbered columns in Table 2. Cols. (6) and (8) exclude patent applications with effective filing dates between 12/8/94-8/8/95. Coefficients and standard errors are multiplied by 100 for $\log$ specifications. 
Table 7: Post-TRIPS Coefficients and Patent Premiums as Measured in Arora et al. 2008

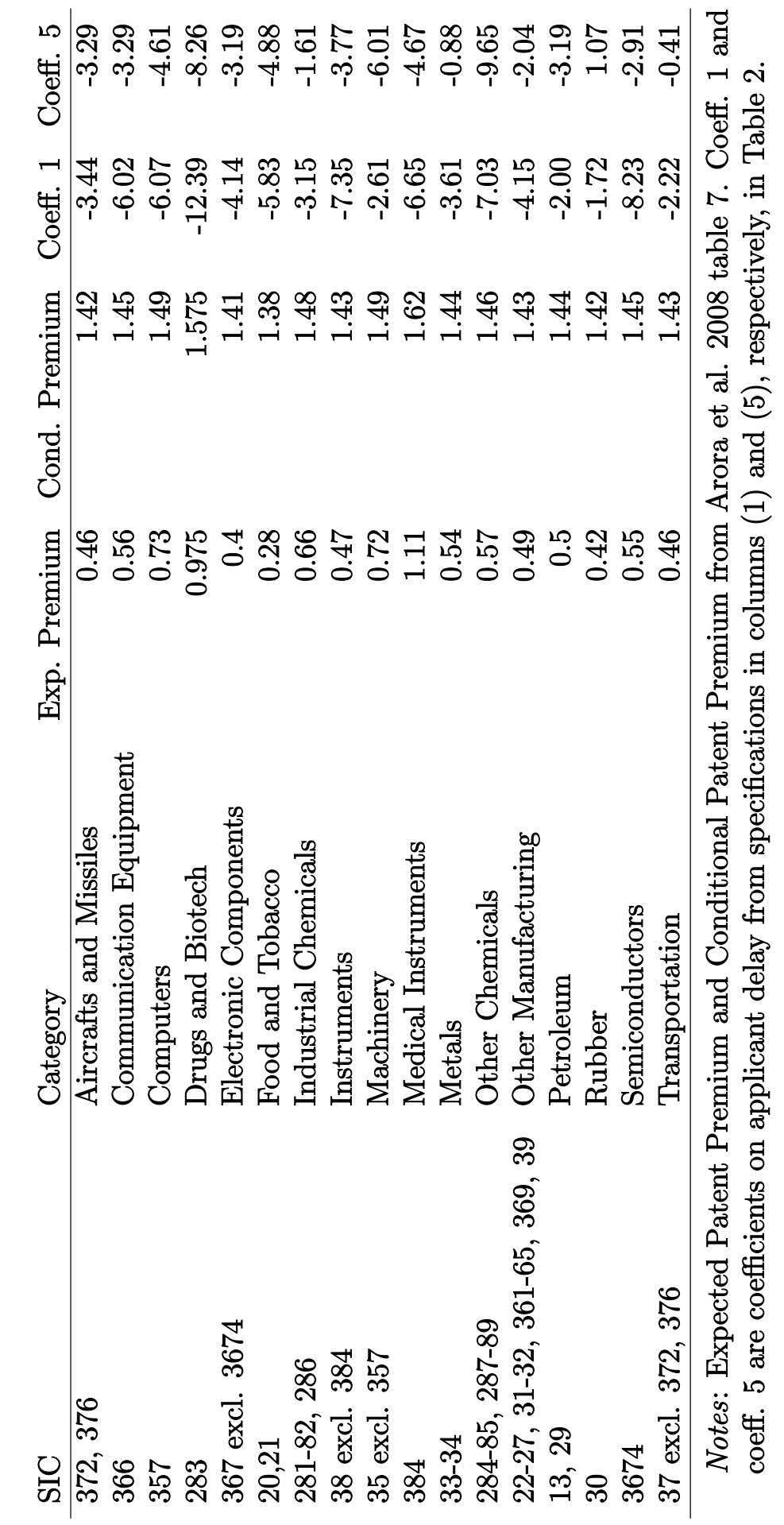




\section{Appendix}

\section{Figures}

Figure A.1: Applicant Delay Coefficient by Month

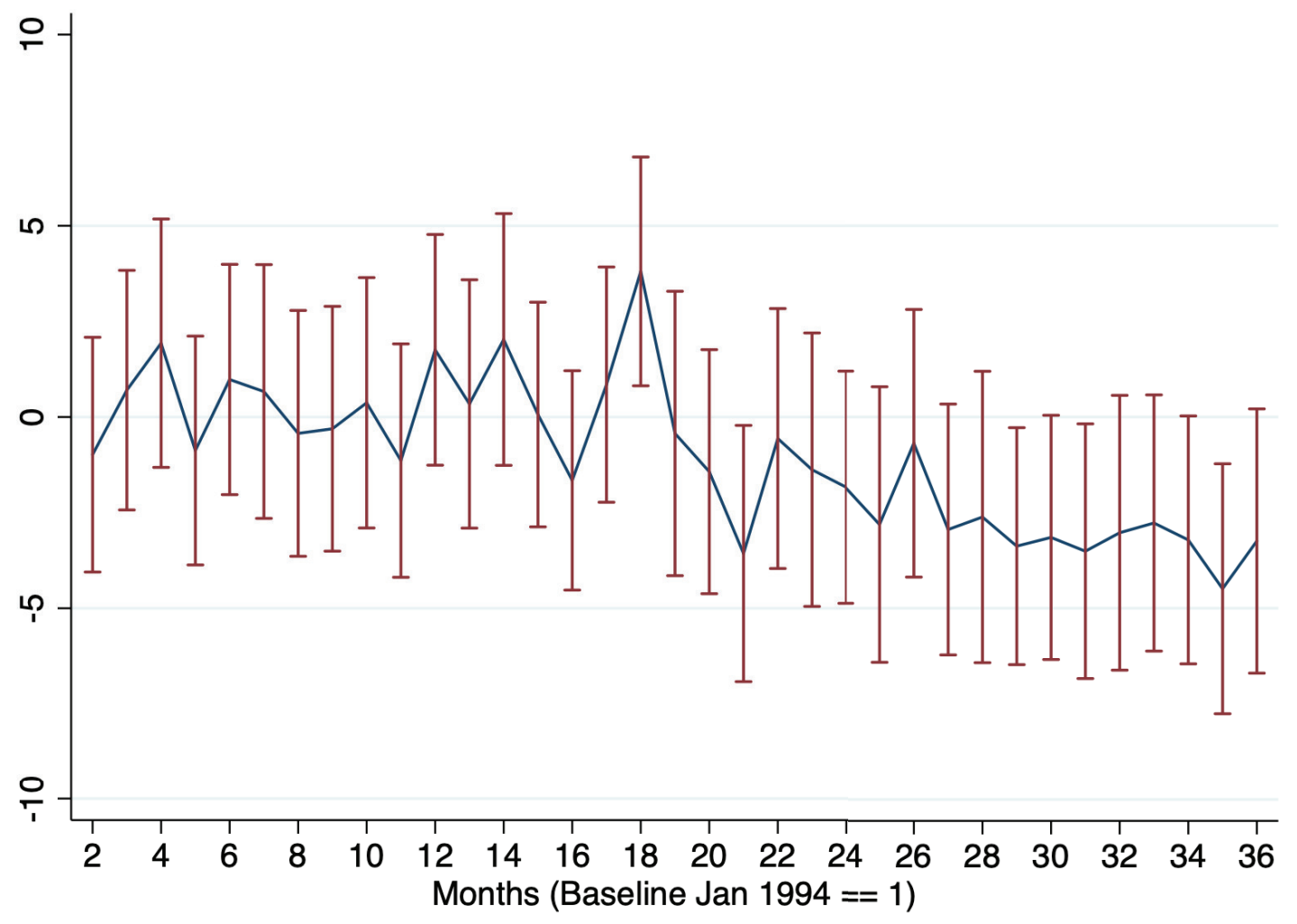

Notes: This figure shows how the applicant delay coefficient changed over time from January 1994 through December 1996. January 1994 is the omitted baseline month, with June 1995 as month 18 (when TRIPS went into effect) and July 1995 as month 19. Each month shows the coefficient (with standard error bands) when regressing applicant delay on month dummies, with all controls and fixed effects as used in the specification in column 5 of Table 2. 


\section{Figure A.2: Pendency by Category}

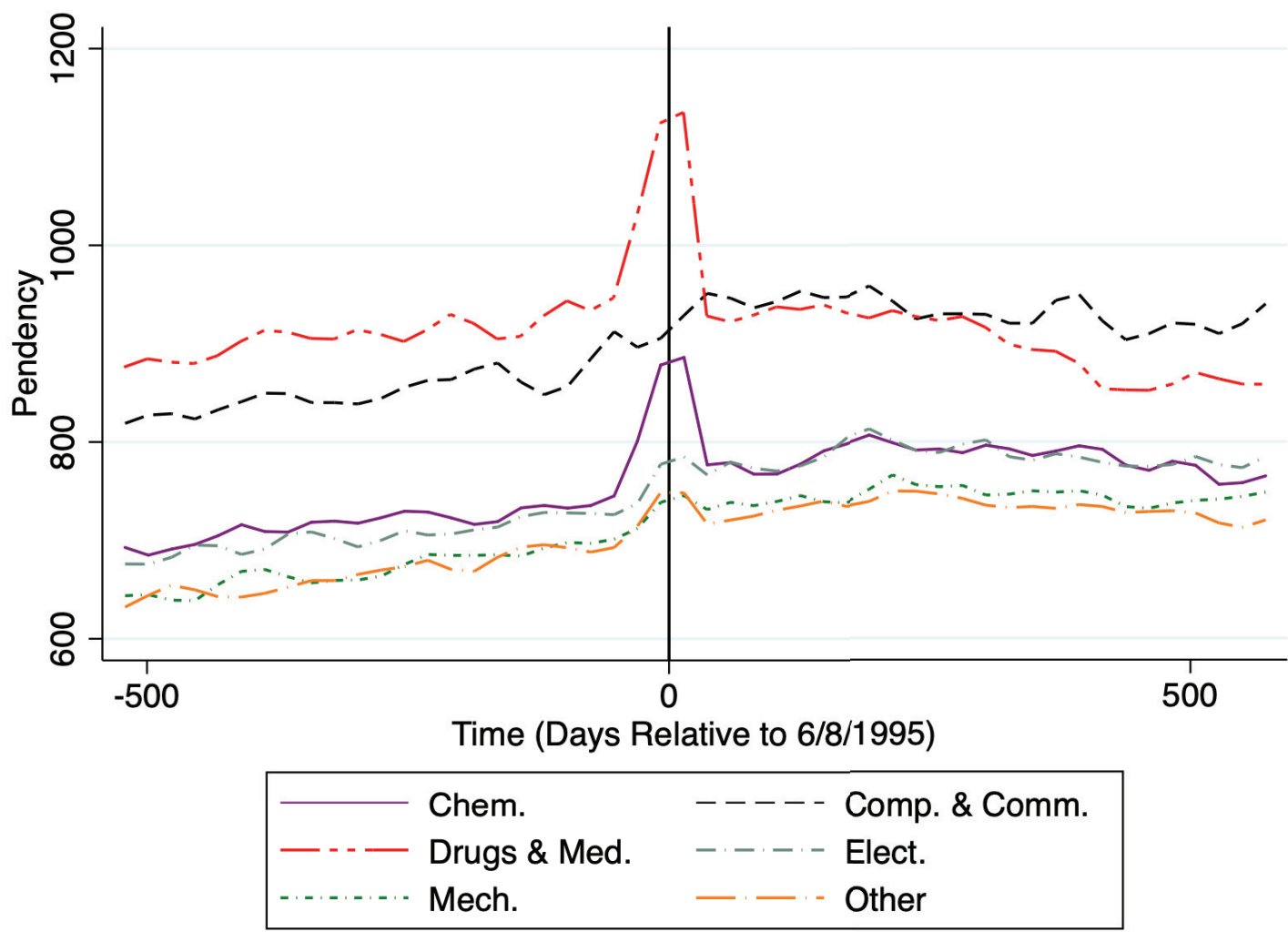

Notes: This graph shows how pendency (i.e., total prosecution time) changed for technologies broken down by NBER category from January 1, 1994, through December 31, 1996. The local polynomial regression is conducted using an Epanechnikov kernel of degree 0 and bandwidth of 14. "0" represents June 8, 1995, when the new TRIPS regime went into effect. 
Figure A.3: Local Polynomial Test for Trend Break in Applicant Delay

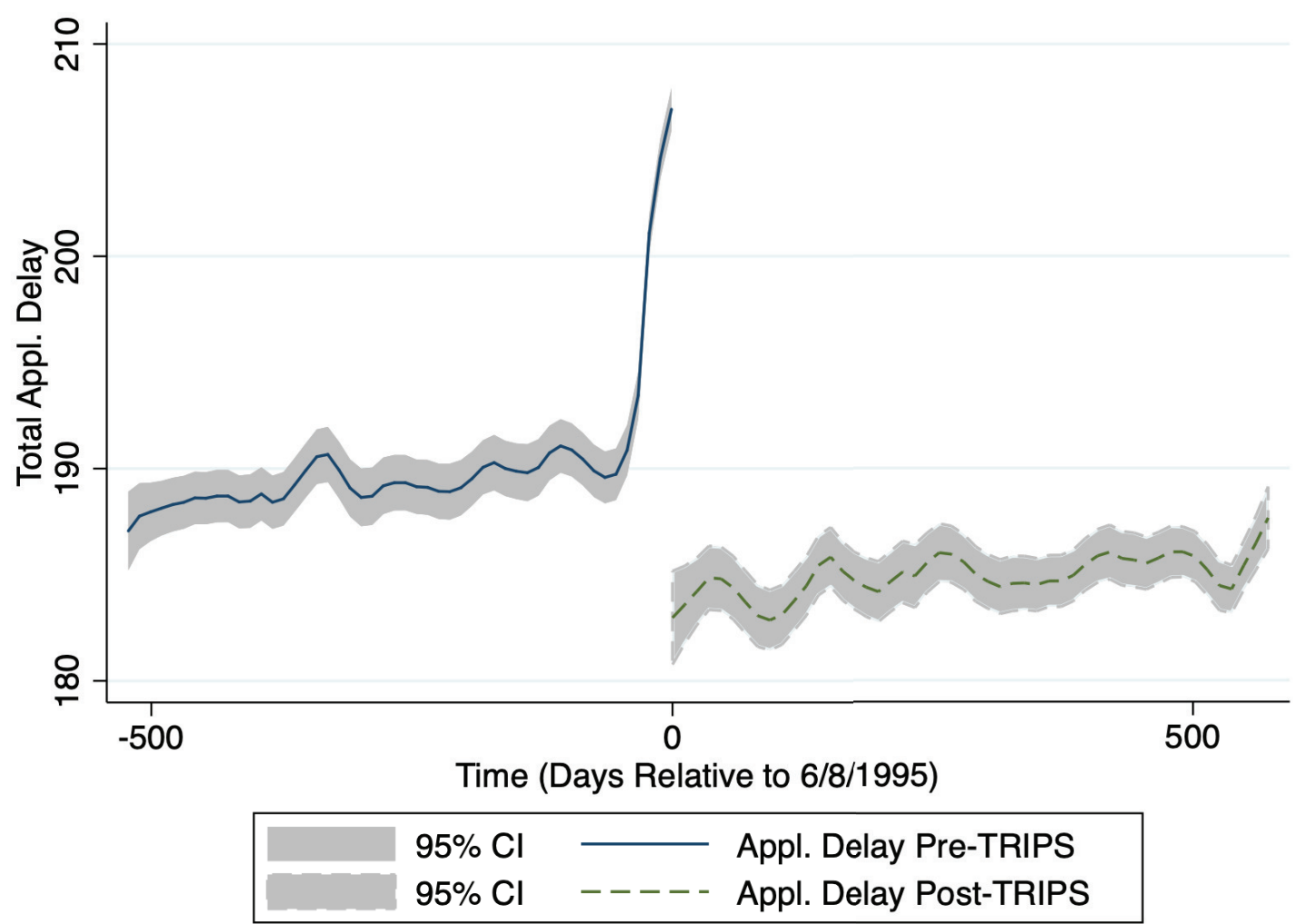

Notes: This graph shows local polynomial regressions to test for a trend break on the date TRIPS went into effect (June 8, 1995). The polynomials use Epanechnikov kernels of degree 0 and bandwidth of 14 . The left polynomial runs from January 1, 1994, to June 7, 1995, and the right polynomial runs from June 8, 1995, to December 31, 1996. Gray areas show $95 \%$ confidence intervals. 


\section{Tables}

Table A.1: Post-TRIPS Coefficient, \% Maintained, and Patent Count Selection Measure Across Subcategories: Alternate Specifications

\begin{tabular}{|c|c|c|c|c|c|}
\hline Subcategory & $\begin{array}{l}\text { Delay } \\
(1)\end{array}$ & $\begin{array}{l}\text { Delay } \\
(2)\end{array}$ & $\begin{array}{c}\text { Log Delay } \\
(3)\end{array}$ & $\begin{array}{c}\text { Log Delay } \\
(4)\end{array}$ & $\%$ Maintain \\
\hline \multicolumn{6}{|l|}{ Chemicals } \\
\hline Agric., Food, Textiles & $-1.23(4.33)$ & $-3.03(4.41)$ & $-2.31(1.89)$ & $-2.59(2.03)$ & 36.60 \\
\hline Coating & $-1.43(1.93)$ & $-2.69(2.01)$ & $-0.51(1.02)$ & $-1.52(1.12)$ & 47.55 \\
\hline Gas & $-1.62(4.01)$ & $-1.17(4.47)$ & $-0.75(2.05)$ & $-0.44(2.24)$ & 44.37 \\
\hline Organic Compounds & $-12.58(2.12)^{* * *}$ & $-10.99(2.28)^{* * *}$ & $-6.57(0.97)^{* * *}$ & $-6.25(1.04)^{* * *}$ & 44.09 \\
\hline Resins & $-9.23(1.48)^{* * *}$ & $-9.60(1.68)^{* * *}$ & $-4.28(0.71)^{* * *}$ & $-4.31(0.79)^{* * *}$ & 50.27 \\
\hline Chem.-Misc. & $-5.76(0.97)^{* * *}$ & $-6.36(1.08)^{* * *}$ & $-3.32(0.46)^{* * *}$ & $-3.66(0.51)^{* * *}$ & 45.70 \\
\hline \multicolumn{6}{|c|}{ Computers \& Communications } \\
\hline Communications & $-7.54(0.98)^{* * *}$ & $-9.17(1.12)^{* * *}$ & $-4.09(0.48)^{* * *}$ & $-4.92(0.53)^{* * *}$ & 60.34 \\
\hline Comp. Hard. \& Software & $-7.50(1.07)^{* * *}$ & $-9.23(1.21)^{* * *}$ & $-3.58(0.50)^{* * *}$ & $-4.43(0.55)^{* * *}$ & 60.38 \\
\hline Computer Peripherals & $-6.43(1.55)^{* * *}$ & $-9.63(1.70)^{* * *}$ & $-2.62(0.73)^{* * *}$ & $-4.27(0.81)^{* * *}$ & 62.25 \\
\hline Information Storage & $-6.85(1.47)^{* * *}$ & $-7.81(1.54)^{* * *}$ & $-3.49(0.68)^{* * *}$ & $-4.26(0.73)^{* * *}$ & 60.13 \\
\hline Elec. Bus. Meth. \& Soft. & $-2.66(2.76)$ & $-4.24(3.09)$ & $-2.13(1.24)^{*}$ & $-2.49(1.39)^{*}$ & 64.00 \\
\hline \multicolumn{6}{|l|}{ Drugs \& Medical } \\
\hline Drugs & $-11.15(1.23)^{* * *}$ & $-9.52(1.34)^{* * *}$ & $-5.30(0.51) * * *$ & $-4.54(0.56)^{* * *}$ & 48.08 \\
\hline Surgery \& Med Inst. & $-4.19(1.56)^{* * *}$ & $-3.75(1.74)^{* *}$ & $-2.42(0.71)^{* * *}$ & $-2.11(0.79)^{* * *}$ & 57.68 \\
\hline Genetics & $-34.08(5.48)^{* * *}$ & $-33.37(5.75)^{* * *}$ & $-19.05(2.98)^{* * *}$ & $-19.83(3.17)^{* * *}$ & 60.95 \\
\hline Drugs and Med.-Misc. & $-4.41(2.92)$ & $-4.16(3.29)$ & $-3.21(1.59)^{* *}$ & $-2.99(1.76)^{*}$ & 53.23 \\
\hline \multicolumn{6}{|l|}{ Electrical \& Electronics } \\
\hline Electrical Devices & $-3.65(1.29) * * *$ & $-4.45(1.47)^{* * *}$ & $-2.03(0.73)^{* * *}$ & $-2.57(0.81)^{* * *}$ & 51.52 \\
\hline Electrical Lighting & $-3.97(2.20)^{*}$ & $-4.36(2.49)^{*}$ & $-1.12(1.09)$ & $-1.43(1.23)$ & 41.49 \\
\hline Measuring and Testing & $-6.83(1.44)^{* * *}$ & $-7.82(1.57)^{* * *}$ & $-4.37(0.78)^{* * *}$ & $-5.53(0.85)^{* * *}$ & 47.21 \\
\hline Nuclear \& X-rays & $-7.05(2.21)^{* * *}$ & $-8.18(2.50)^{* * *}$ & $-3.14(1.27)^{* *}$ & $-4.01(1.42)^{* * *}$ & 51.80 \\
\hline Power Systems & $-5.16(1.28)^{* * *}$ & $-6.08(1.45)^{* * *}$ & $-2.94(0.71)^{* * *}$ & $-3.36(0.78)^{* * *}$ & 52.93 \\
\hline Semiconductor Devices & $-9.46(1.46)^{* * *}$ & $-11.60(1.67)^{* * *}$ & $-4.52(0.68)^{* * *}$ & $-5.56(0.75)^{* * *}$ & 63.60 \\
\hline Elec.-Misc. & $-5.71(1.58)^{* * *}$ & $-7.58(1.82)^{* * *}$ & $-2.69(0.71)^{* * *}$ & $-3.59(0.79)^{* * *}$ & 56.63 \\
\hline \multicolumn{6}{|l|}{ Mechanical } \\
\hline Mat. Proc. \& Handling & $-0.44(1.28)$ & $-1.38(1.38)$ & $-0.96(0.65)$ & $-1.54(0.71)^{* *}$ & 41.24 \\
\hline Metal Working & $-2.70(1.73)$ & $-4.38(1.93)^{* *}$ & $-2.05(0.89)^{* *}$ & $-2.78(0.99)^{* * *}$ & 45.80 \\
\hline Motors \& Engines + Parts & $-2.37(1.79)$ & $-3.08(2.12)$ & $-0.93(0.77)$ & $-1.29(0.86)$ & 45.51 \\
\hline Optics & $-3.59(2.01)^{*}$ & $-6.70(2.34)^{* * *}$ & $-1.83(0.99)^{*}$ & $-3.06(1.09)^{* * *}$ & 50.00 \\
\hline Transportation & $-1.64(1.54)$ & $-1.86(1.73)$ & $-1.73(0.84)^{* *}$ & $-1.86(0.95)^{* *}$ & 36.14 \\
\hline Mech.-Misc. & $-3.12(1.35)^{* *}$ & $-4.28(1.51)^{* * *}$ & $-1.61(0.70)^{* *}$ & $-2.21(0.78)^{* * *}$ & 41.02 \\
\hline \multicolumn{6}{|l|}{ Others } \\
\hline Agric., Husbandry, Food & $-3.01(2.14)$ & $-5.41(2.38)^{* *}$ & $-3.27(1.14)^{* * *}$ & $-5.05(1.25)^{* * *}$ & 35.43 \\
\hline Amusement Devices & $3.65(2.76)$ & $2.89(2.96)$ & $0.81(1.44)$ & $1.05(1.63)$ & 28.60 \\
\hline Apparel \& Textile & $-4.76(2.36)^{* *}$ & $-4.16(2.69)$ & $-3.36(1.17)^{* * *}$ & $-3.06(1.32)^{* *}$ & 30.36 \\
\hline Earth Working \& Wells & $-7.71(3.06)^{* *}$ & $-4.59(3.04)$ & $-3.21(1.52)^{* *}$ & $-2.61(1.70)$ & 49.46 \\
\hline Furniture, House Fixtures & $-2.71(1.76)$ & $-2.31(2.01)$ & $-2.18(0.99)^{* *}$ & $-2.08(1.12)^{*}$ & 27.84 \\
\hline Heating & $-6.56(3.03)^{* *}$ & $-7.72(3.48)^{* *}$ & $-3.05(1.52)^{* *}$ & $-3.89(1.72)^{* *}$ & 40.43 \\
\hline Pipes \& Joints & $-5.17(3.69)$ & $-6.86(4.16)^{*}$ & $-3.36(1.50)^{* *}$ & $-4.64(1.68)^{* * *}$ & 47.75 \\
\hline Receptacles & $-2.88(2.31)$ & $-3.98(2.75)$ & $-2.29(1.13)^{* *}$ & $-3.24(1.26)^{* *}$ & 32.95 \\
\hline Other-Misc. & $-6.27(0.94)^{* * *}$ & $-8.08(1.06)^{* * *}$ & $-3.26(0.48)^{* * *}$ & $-4.13(0.53)^{* * *}$ & 40.74 \\
\hline
\end{tabular}

Notes: Cols. (1) and (2) ((3) and (4)) are coefficients when applicant delay (log applicant delay) is regressed on a post-TRIPS dummy, as in specifications in the same-numbered columns in Table 2. Cols. (2) and (4) exclude patent applications with effective filing dates between 12/8/94-8/8/95. Coefficients and standard errors are multiplied by 100 for $\log$ specifications. 


\section{References}

David S. Abrams. Did TRIPS Spur Innovation? An Analysis of Patent Duration and Incentives to Innovate. University of Pennsylvania Law Review, 157(6):pp. 16131647, 2009. ISSN 00419907. URL http://www.jstor.org/stable/40380275.

David S. Abrams, Ufuk Akcigit, and Jillian Popadak. Understanding the Link between Patent Value and Citations: Creative Destruction or Defensive Disruption? April 8, 2013.

John R. Allison, Mark A. Lemley, Kimberly A. Moore, and R. Derek Trunkey. Valuable Patents. Geo. $L j$, 92:435, 2003.

Ashish Arora, Marco Ceccagnoli, and Wesley M. Cohen. R\&d and the patent premium. International Journal of Industrial Organization, 26(5):1153-1179, 2008.

James Bessen. The Value of U.S. Patents by Owner and Patent Characteristics. Research Policy, 37(5):932-945, 2008.

Michele Boldrin and David K Levine. Against Intellectual Monopoly. Cambridge University Press Cambridge, 2008.

Eric Budish, Benjamin N. Roin, and Heidi Williams. Do Fixed Patent Terms Distort Innovation? Evidence from Cancer Clinical Trials. Technical report, National Bureau of Economic Research, 2013.

Ian A. Calvert and Michael Sofocleous. Interference Statistics for Fiscal Years 1992 to $1994,1995$. 
Wesley M Cohen, Richard R Nelson, and John P Walsh. Protecting their intellectual assets: Appropriability conditions and why us manufacturing firms patent (or not). Technical report, National Bureau of Economic Research, 2000.

Dennis Crouch. Timing of the Notice of Allowance, Issue Fee Payment, and Patent Issuance. http://www. patentlyo.com/patent/2010/06/timing-of-...html, June 9, 2010.

Michael D. Frakes and Melissa Wasserman. Does Agency Funding Affect Decisionmaking?: An Empirical Assessment of the PTO's Granting Patterns. Vanderbilt Law Review, 66(1):pp. 67-149, 2013.

Henry Grabowski. Patents, Innovation and Access to New Pharmaceuticals. Journal of International Economic Law, 5(4):849-860, 2002. doi: 10.1093/jiel/5.4.849. URL http://jiel . oxfordjournals . org/content/5/4/849. abstract.

Zvi Griliches, Ariel Pakes, and Bronwyn H Hall. The value of patents as indicators of inventive activity, 1986.

Bronwyn H. Hall, Adam B. Jaffe, and Manuel Trajtenberg. The NBER Patent Citation Data File: Lessons, Insights and Methodological Tools. Technical report, National Bureau of Economic Research, 2001.

Leonid Kogan, Dimitris Papanikolaou, Amit Seru, and Noah Stoffman. Technological innovation, resource allocation, and growth. The Quarterly Journal of Economics, 132(2):665-712, 2017.

Jean O. Lanjouw, Ariel Pakes, and Jonathan Putnam. How to Count Patents and Value Intellectual Property: The Uses of Patent Renewal and Application Data. 
The Journal of Industrial Economics, 46(4):405-432, 1998a. ISSN 1467-6451. doi: 10.1111/1467-6451.00081. URL http://dx.doi.org/10.1111/1467-6451 .00081.

Jean O Lanjouw, Ariel Pakes, and Jonathan Putnam. How to count patents and value intellectual property: The uses of patent renewal and application data. The Journal of Industrial Economics, 46(4):405-432, 1998b.

Mark A. Lemley. An Empirical Study of the Twenty-Year Patent Term. AIPLA Quarterly Journal, 22(3-4):pp. 369-424, 1994.

Richard C. Levin, Alvin K. Klevorick, Richard R. Nelson, Sidney G. Winter, Richard Gilbert, and Zvi Griliches. Appropriating the Returns from Industrial Research and Development. Brookings Papers on Economic Activity, 1987(3):pp. 783-831, 1987. ISSN 00072303. URL http://www.jstor.org/stable/2534454.

Travis J Lybbert and Nikolas J Zolas. Getting patents and economic data to speak to each other: An ?algorithmic links with probabilities? approach for joint analyses of patenting and economic activity. Research Policy, 43(3):530-542, 2014.

Kimberly A Moore. Worthless Patents. George Mason University School of Law Working Papers Series, page 27, 2005.

W. D. Nordhaus. The Optimal Life of a Patent. Cowles Foundation for Research in Economics, Yale University, (No. 241), 1967.

Ariel Pakes. Patents as options: Some estimates of the value of holding european patent stocks. Econometrica, 54(4):755-784, 1986. ISSN 00129682, 14680262. URL http://www.jstor.org/stable/1912835. 
Ariel Pakes and Mark Schankerman. The rate of obsolescence of patents, research gestation lags, and the private rate of return to research resources. In $R \mathscr{E} D$, patents, and productivity, pages 73-88. University of Chicago Press, 1984.

Ariel Pakes, Margaret Simpson, Kenneth Judd, and Edwin Mansfield. Patent renewal data. Brookings papers on economic activity. Microeconomics, 1989:331-410, 1989.

Benjamin N. Roin. The Case for Tailoring Patent Awards Based on the Time-toMarket of Inventions. UCLA Law Review, 2014.

Mark Schankerman. How Valuable is Patent Protection? Estimates by Technology Field. The RAND Journal of Economics, 29(1):pp. 77-107, 1998. ISSN 07416261. URL http://www.jstor.org/stable/2555817.

Mark Schankerman and Ariel Pakes. Estimates of the value of patent rights in european countries during thepost-1950 period, 1985.

Frederic M Scherer. Nordhaus' Theory of Optimal Patent Life: A Geometric Reinterpretation. The American Economic Review, 62(3):422-427, 1972.

U.S. Patent \& Trademark Office. Receipts and Dispositions by Technology Center for Ex Parte Appeals FY 1998, 1998.

Charles E. Van Horn. Effects of GATT and NAFTA on PTO Practice. http://www .uspto.gov/web/offices/com/doc/uruguay/URPAPER.html, 1995.

Bruno Van Pottelsberghe, Herman Denis, Dominique Guellec, et al. Using patent counts for cross-country comparisons of technology output. Technical report, ULBUniversite Libre de Bruxelles, 2001.

R. Polk Wagner. On Software Regulation. Southern California Law Review, 78:457, 2006. 